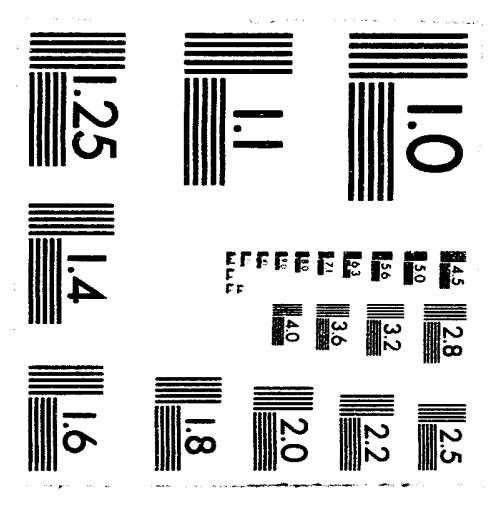



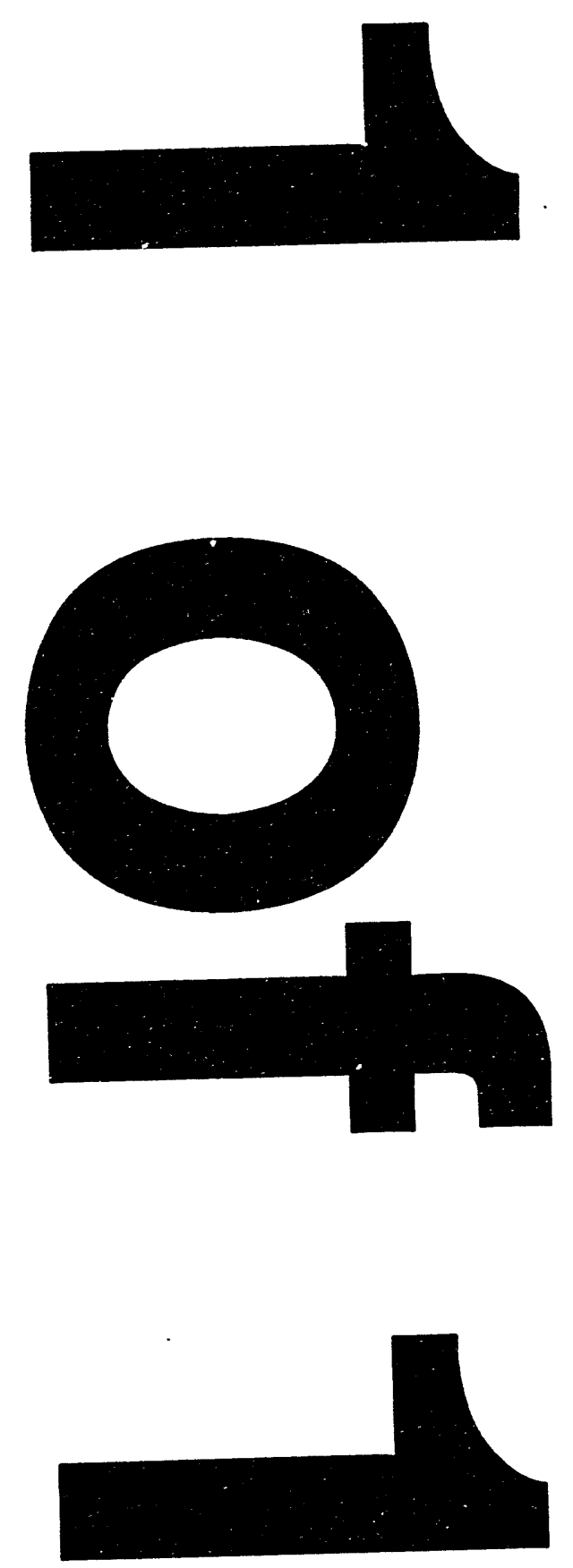


\section{DISCLAIMER}

This report was prepared as an account of work sponsored by an agency of the United States Government. Neither the United States Government nor any agency thereof, nor any of their employees, makes any warranty, express or implied, or assumes any legal liability or responsibility for the accuracy, completeness, or usefulness of any information, apparatus, product, or

process disclosed, or represents that its use would not infringe privately owned rights. Reference herein to any specific commercial product, process, or service by trade name, trademark, manufacturer, or otherwise does not necessarily constitute or imply its endorsement, recommendation, or favoring by the United States Govertment or any agency thereof. The views and opinions of authors expressed herein do not necessarily state or reflect those of the United States Government or any agency thereof.

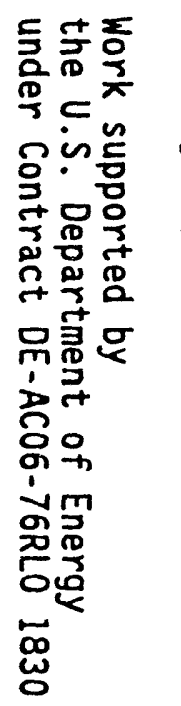

号芯怘。

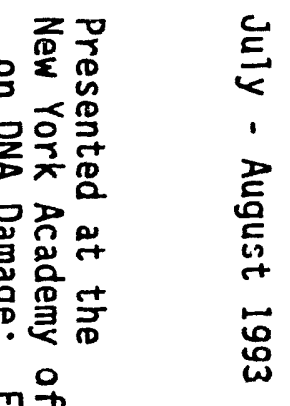

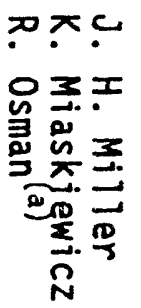

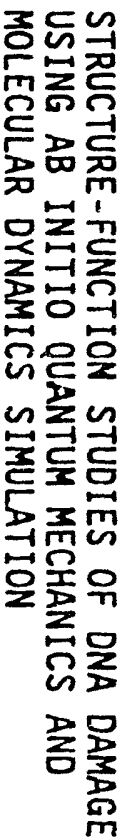

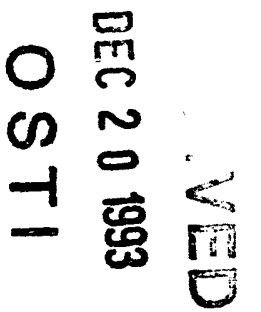




\title{
STRUCTURE-FUNCTION STUDIES OF DNA DAMAGE USING AB INITIO GUANTUM MECHANICS AND MOLECULAR DYNAMICS SIMULATION
}

\author{
John Miller and Karol Miaskiewicz \\ Biology and Chemistry Department \\ Pacific Northwest Laboratory \\ Richland, Washington \\ and \\ Roman Osman \\ Department of Physiology and Biophysics \\ Mount Sinal School of Medicine of the City University of New York \\ New York, New York
}

\begin{abstract}
Studies of ring-saturated pyrir idine base lesions are used to illustrate an integrated modeling approach that combines quantum-chemical calculations with molecular dynamics simulation. Electronic-structure calculations on the lesions in isolation reveal strong conformational preferences due to interactions between equatorial substituents to the pyrimidine ring. Large distortions of DNA should result when these interactions force the methyl group of thymine to assume an axial orientation, as is the case for thymine glycol but not for dihydrothymine. Molecular dynarnics simulations of the dodecamer d(CGCGAA.TCGCG $)_{2}$ with and without a ring-saturated thymine lesion at position $T 7$ support this conclusion. Implications of these studies for recognition of thymine lesions by endonuclease III are also discussed.
\end{abstract}

\section{INTRODUCTION}

DNA in living cells is exposed continuously to a number of environmental agents which may include UV and ionizing radiation as well as various chemical species. In many cases, the mechanism of action of these agents involves the generation of free radicals that attack DNA and produce a variety of lesions including sugar and base modifications, strand 
breaks, and cross-links. Some active oxygen radicals (e.g. $\mathrm{O}_{2} \cdot \cdot \mathrm{OH}$ ) are also generated endogenously during cellular aerobic metabolism and the damage they cause may be an important factor in aging and age-dependent diseases including cancer 1.2.3.4.

Pyrimidine bases are a major target of free-radical induced DNA damage. Free radicals add easily to the $\mathrm{C}(5) \mathrm{C}(6)$ unsaturated bond of pyrimidines. The base centered radicals formed in such addition reactions can be further transformed to yield different stable products. One group of stable products, which includes 5,6-dihydroxy-5.6dihydropyrimidines (pyrimidine glycols), 5,6-dihydropyrimidines, 5-hydroxy-5.6dihydropyrimidines and 6-hydroxy-5.6-dihydropyrimidines loften referred as pyrimidine hydrates), is characterized by p!rmidine derivatives with a saturated ring. These pyrimidine lesions have been observed in DNA after radiolysis, UV irradiation or oxidation by chemicals. Pyrimidine glycols, 5.6-dihydropyrimidines, and 5-hydroxy-5,6dihydropyrimidines have been detected upon radiolysis of polynucleotides and DNA both in vitro (reviewed by 5.6 ) and in vivo 7.8 . On the other hand pyrimidine hydrates are a common product of UV damage to DNA 9.10. Similar products to those seen in DNA radiolysis are also observed in the damage caused by oxidative chemicals including some antibiotics 11 . Substantial amounts of endogenously generated thymine glycol are also detected in the human and animals urine 2.

The pyrimidine DNA lesions may cause significant biological consequences including mutagenesis and inhibition of replication. Surprisingly, the biological consequences of ring-saturated pyrimidine lesions can be very different. Strong inhibition of DNA polymerase 1 activity has been observed for thymine glycol 12.13.14.15, which is in sharp contrast to the chemically similar lesion 5.6-dihydrothymine that is at most a very weak block for polymerase I action 16. Similarly, only slight inhibition of DNA replication by UV-induced thymine hydrate (6-hydroxy-5,6-dihydrothymine) was detected ${ }^{1 i}$. The 5 -triphosphate of dihydrothymine can serve as an efficient substrate for DNA polymerase I but the $5^{\prime}$-triphosphate of thymidine glycol is not incorporated into DNA by this polymerase 18. Addition evidence that DNA structural perturbations by chemically related pyrimidine 
lesions are very different comes from the activity of the UrTABC nuclease complex toward these leions. This repair enzyme, which is generally considered to be the enzyme responsible for removing bulky adducts that cause extensive distortions to DNA structure 19, 20, recognizes and incises DNA that contains thymine glycol 20. 2! but it is not active toward 5.6-dihydrothymine 21 .

Although the biological consequences of damaged pyrimidine DNA bases have been studied quite extensively, a mechanistic understanding of the differences in the biological activity of chemically related lesions such as the ring-saturated pyrimidines has not been achieved. Theoretical studies of the effects of damaged bases on the conformation and dynamics of DNA, tested whenever possible by experimental data, can make a siginificant contribution to this endeavor. This paper describes quantum-chemical calculations that show the energetic basis for the conformational preferences of ring-saturated pyrimidines in isolation. The most stable stereoisomers of the isolated thymine lesions have been incorporated into the dodecamer d(CGCGAATTCGCG) 2 at the $T 7$ position. Molecular dynamics simulations suggest that the major source of DNA distortion by ring-saturated thymine lesions is their nonplanarity, which varies greatly depending on which of the substituents at $C(5)$ and $C(6)$ are axially oriented.

The principal repair pathway for pyrimidine lesions is the base-excision mechanism that involves the release of a modified base by a DNA N-glycosylases and then hydrolysis of the phosphodiester bond by apurinic/apyrimidinic (AP) endonucleases. Endonuclease III of Escherichia coli, which requires double stranded DNA for its activity but no cofactor or metal ions, has both of these activities. It catalyses the hydrolysis of base-sugar bonds to liberate damaged pyrimidines and cleaves the phosphodiester bond $3^{\prime}$ to the lesion by $\beta$ elimination in a concerted way 22. Interestingly, the enzyme repairs a broad spectrum of pyrimidine lesions formed by ring saturation and fragmentation even though these lesions behave so differently in many other aspects of their biological activity as discussed above. Activities of endonuclease III towards thymine glycols, 5.6-dihydrothymine, urea, cytosine and thymine hydrates have been observed 22.23.24. 25. Thymine glycol strongly inhibits 
endonuclease III activity towards DNA containing thymine glycol and urea 22 indicating that thymine glycol binds to the same site of endonuclease III as lesioned DNA. This observation together with atomic coordinates for the enzyme obtained from recent crystalographic data 26 are the basis of our model of the complex between endonuclease III and DNA containing thymine glycol.

\section{gUANTUM-CHEMICAL CALCULATIONS OF STRUCTURAL PROPERTIES OF PYRIMIDINE LESIONS}

Free-radical addition to the $C(5) C(6)$ double bond of pyrimidines leads to a class of nonplanar ring-saturated lesions which includes 5,6-dihydroxy-5,6-dihydropyrimidines (pyrimidine glycols), 6-hydroxy-5,6-dihydropytimidines (pyrimidine hydrates). 5-hydroxy-5,6-dihydropyrimidines, and 5.6-dihydropyrimidines. Each of these lesions can exist in several stereoisomeric forms which may be energetically distinct depending on the environment. The stereochemistry of thymine glycol (Tg) and thymine hydrate are particularly complex because they have two asımmetric cabon centers while rest of the lesions have only one. The stereochemsitry of $\mathrm{Tg}$ is illustrated in Fig.(1). Each asymmetric carbon gives rise to two stereoisomers; however, since the ring is nonplanar, each isomer can exist in two conformations with different substituents in the equatorial and axial orientations. In the absence of an external perturbation. such as deoxyribose or other components of DNA, the eight stereoisomers of $\mathrm{Tg}$ can be grouped into four pairs of degenerate enantiomers. Hence, for quantum-chemical studies of the relative stability of $\mathrm{Tg}$ stereoisomers in isolation, only the four conformations on the left-hand side of Fig.(1) need to be considered. These conformations can be denoted as $5-\mathrm{OH}_{\mathrm{eq}}-6-\mathrm{OH}_{\mathrm{eq}} \cdot 5-\mathrm{OH}_{\mathrm{ax}}-6-\mathrm{OH}_{\mathrm{ax}}, 5-$ $\mathrm{OH}_{\mathrm{eq}}-6-\mathrm{OH}_{\mathrm{ax}}$, and $5-\mathrm{OH}_{\mathrm{ax}}-6-\mathrm{OH}_{\mathrm{eq}}$ according to the pseudo equatorial and pseudo axial orientation of the hydroxyl groups at $C(5)$ and $C(6)$. The stereochemistry of thymine hydrates is analagous to $\mathrm{Tg}$ with $5-\mathrm{OH}_{\mathrm{eq}}$ and $5-\mathrm{OH}_{\mathrm{ax}}$ replaced by $5-\mathrm{Met}_{\mathrm{eq}}$ and $5-\mathrm{Met}_{\mathrm{ax}}$, respectively, to denote the orientation of the methyl group at $C(5)$. 
Only two conformations must be considered to calculate the relative stability of isolated stereoisomers of ring-saturated pyrimidine lesions with only one asymmetric carbon center. For uracil and cytosine hydrates, we use $6-\mathrm{OH}_{\mathrm{eq}}$ and $6-\mathrm{OH}_{\mathrm{ax}}$ to denote these energetically distinct conformers. Similarly, $5-\mathrm{OH}_{\mathrm{eq}}$ and $5-\mathrm{OH}_{\mathrm{ax}}$ can be used to label the energies that we calculate for stereoisomers of 5-hydroxy-5.6-dihydropyrimidines. The energetically distinct conformations of 5.6-dihydrothymine in isolation will be denoted by 5-Meteq and 5-Met - $_{a x}$. All of our quantum-chemical calculations were performed using the GAUSSIAN90 27 package for ab initio calculations. Geometries were optimized without constrains at the HF/6-31G level and single-point calculations at MP2/6-31G* level were done on the optimized structures. Solvation energies were calculated using a representation of the solvent as a dielectric continuum and the solute as a cavity in the solvent 28 . The charge distribution of the solute is described as a collection of point charges that induce a reaction field in the continuum. The point charges were obtained from a Mulliken population analysis of a 6-31G wave function. Our resuits are summarized in Table 1 where the energies calculated at various levels of approximation are given in $\mathrm{kcal} / \mathrm{mole}$ relative to the most stable comformation.

Table 1 shows that 5.6-dihydrothymine prefers a confromation with the methyl group at $\mathrm{C}(5)$ in an equatorial orientation. The energy difference for this structural perference is about an order of magnitude smaller than that found for the other ringsaturated pyrimidine lesions which involve addition of hydroxyl groups rather than hydrogen atoms. The $\mathrm{OH}$ group of the hydroxy-dihydro-pyrimidines shows different stereochemical preference at $\mathrm{C}(5)$ and $\mathrm{C}(6)$. A pseudoaxial orientation of $\mathrm{OH}$ is preferred at $\mathrm{C}(6)$, whereas a pseudoequatorial $\mathrm{OH}$ is energetically favored at $\mathrm{C}(5)$. Interactions between polar groups in the equatorial plane are primarly responsible for these preferences. The interaction between the equatorial $\mathrm{OH}$ group at $\mathrm{C}(5)$ and the adjacent $\mathrm{C}(4) \mathrm{O}(4)$ carbonyl bond in uracil can be ciearly seen from the structure of $5-\mathrm{OH}_{\mathrm{eq}}-5,6$-dihydrouracil presented in Fig.(2a). The dipoles of the $\mathrm{OH}$ and $\mathrm{C}(4) \mathrm{O}(4)$ bonds are almost in an ideal antiparallel orientation, producing a favorable electrostatic interaction. A similar interaction occurs in 
thymine denvatives. An equatorial orientation of $\mathrm{OH}$ groups at $\mathrm{C}(5)$ is also preferred in cytosine derivatives because the amino group at $\mathrm{C}(4)$ gives rise to a similar favorable electrostatic interaction between the $\mathrm{C}(5) \mathrm{O}(5)$ and the $\mathrm{N}(4) \mathrm{H}(4)$ bond dipoles. The $\mathrm{OH}$ group in an equatorial orientation at $\mathrm{C}(6)$ experiences an unfavorable electrostatic interaction with the $\mathrm{N}(1) \mathrm{H}(1)$ dipole since the direction of the $\mathrm{N}(1) \mathrm{H}(1)$ bond dipole is opposite to that of the $\mathrm{C}(4) \mathrm{O}(4)$ bond. To minimize this unfavorable interaction the $\mathrm{OH}$ bond dipole is rotated away from the $\mathrm{N}(1) \mathrm{H}(1)$ bond as is lllustrated by the structure of $6-\mathrm{OH}_{\mathrm{eq}}-5,6$-dihydrouracil in Fig.(2b).

The calculated conformational preferences described above agree very well with $x$-ray crystallograpic data on cis- thymidine glycol 29 which show both the $5-\mathrm{CH}_{3}$ and $6-\mathrm{OH}$ groups in the pseudo axial orientation. In addition, an axial onentation of $\mathrm{OH}$ at $\mathrm{C}(6)$ is suggested by NMR spectra on a variety of 5,6-saturated derivatives of uracil 30 and thymine 31 . The structural preferences calculated for 5.6-dihydrothymire are also in good agreement with $\mathrm{x}$-ray 32 and NMR data 33 which indicate that the methyl group at $\mathrm{C}(5)$ prefers the pseudo equatorial orientation.

Our caiculations predict the changes in pyrimidine structure that are expected from saturation of the $\mathrm{C}(5) \mathrm{C}(6)$ bond. The bond length increases by about $0.2 \AA$ and bond angles at $C(5)$ and $C(6)$ decrease to aporoximatly the tetrahedral values. The pyrimidine ring adopts a half-chair conformation, with $\mathrm{C}(5)$ and $\mathrm{C}(6)$ on opposite sides of the mean plane passing through the $\mathrm{N}(1) \mathrm{C}(2) \mathrm{N}(3) \mathrm{C}(4)$ atoms. The rms deviation of these atoms from the calculated mean plane was between 0.02 and $0.06 \AA$ for all of the calculated structures. Calculated displacements of the $C(5)$ atom from this plane were between 0.22 and $0.27 \dot{A}$. The $C(6)$ atom is aisplaced between 0.43 and $0.48 \AA$ in the opposite direction.

In spite of the changes in the $\mathrm{C}(5) \mathrm{C}(6)$ region, the structure of the base-paining regions of the pyrimidine bases is very well preserved in the ring-saturated pyrimidine lesions that we have studied. Cytosine derivatives may be an exception to this general finding. Small distortions in the geometry of the amino group may contribute to a slight weakening of the hydrogen bond to guanine. Changes of the electronic charge distribution in the base-pairing 
regions are negligible in all cases. Based on these results, one may expect a low mutagenic potential for ring-saturated phyrimidine lesions; nevertheless, it should be noted that mutagenicity can be caused by steric distortions of DNA as well as by changes in basepairing ability of the pyrimidine base itself.

Variations in the both magnitude and the direction of pyrmindine-base dipole moments result from saturation of the $C(5) C(6)$ bond; however, we do not believe that these changes in base dipole moments are the source of the biological effects observed from these ring-saturated pyrimidine lesions. The molecular dynamics simulations of a DNA

dodecamer with different thymine lesions described in the next section strongly support the idea that nonplanarity is the primary source of these effects. Our results particularly emphasize the importance of hydroxylated thymine lesions. In constrast to hydroxylated derivatives of cytosine and uracil where the axial position at $C(5)$ is always occupied by a hydrogen atom, this position is occupied by a much bulkier methyl group when an OH group is present at $\mathrm{C}(5)$ of thymine. This means that larger DNA distortions are anticipated for thymine glycol and 5-hydroxy-5.6-dihydrothymine than for cytosine lesions and other thymine lesions. These conclusions from our quantum calculations, which are consistent with the experimental data on biological activity discussed above, have been tested by molecular dynamics simulations that are decribed in the next section.

\section{MOLECULAR DYNAMICS SIMULATION OF JNA CONTAINING RING-SATURATED THYMINE LESIONS}

The quantum-chemical calculations discussed above provide useful information about the structure and properties ring-saturated pyrimidine lesions that is not easily available experimentally. They also provide the input data needed for molecular dynamics simulations (MDS) of DNA sequences containing these lesions. The dodecamer d(CGCGAATTCGCG $)_{2}$ was choosen for these studies because this sequence, which contains the EcoRI recognition site, has been extensively studied experimentally in both solid state and solution as well as being the subject of numerous MDS, including our own work 34 
Starting from the ideal right-handed Arnott B-DNA geometry, MDS have been carried out on the dodecamer d(CGCGAATTCGCG $)_{2}$ with T7 replaced by one of the following lesioned thymine bases: 5-hydroxy-5,6-dihydrothymine, 6-hydroxy-5,6-dihydrothymine, 5,6-dihydroxy-5,6-dihydrothymine and 5,6-dihydrothymine. The lesions were taken in their most stable conformations as predicted by the ab inito quantum-chemical calculations described in the previous section. Atomic charges were obtained by fitting to the electrostatic potential evaluated from the quantum-chemical wavefunction. Energy minimization and MDS were performed with the AMBER4.0 program 35 using the standard unmodified all-atom force-field parameters for nucleic acids included in the program. The ring geometry of lesions was constrained to the half-chair geometry predicted by our quantum-chemical calculations and observed in crystal structures of thymine glycol and 5.6-dihydrothymine. When this constraint is removed. MDS of DNA containing these lesions predict significant distortions of the ring if the standard AMBER force field parameters are used with $\mathrm{sp}^{3}$-type carbon atoms at $\mathrm{C}(5)$ and $\mathrm{C}(6)$ instead of the native $\mathrm{sp}^{2}$ type. Existing experimental data are not adequate to determine if these distortions are reasonable; therefore, while we continue to carry out simulations with constraints on the ring geometry of lesions, we are also developing new force field parameters for the ring-saturated pyrimidines that are based on quantum-chemical calculations of the barriers for the ring inversion in saturated pyrimidines.

$22 \mathrm{Na}^{+}$ions were placed around the DNA dodecamer containing the modified thymine base and the system of DNA and ions was placed in a rectangular cube of water molecules. Periodic boundary conditions were applied within a constant volume algorithm. After minimization, the system was heated from 0 to $300 \mathrm{~K}$ in ten 0.2 ps runs followed by a $1.0 \mathrm{ps}$ run at $300 \mathrm{~K}$. This initial $3.0 \mathrm{ps}$ of simulation insures equilibration of the system and removes steric strain that could remain after minimization. After 'heating', MDS were carried out for 120 ps using the constant temperature algorithm with a bath temperature of $300 \mathrm{~K}$. The final 60 ps of the simulations were used for structural analysis. 
As illustrated in Fig.(3), ring-saturated pyrimidine lesions can be incorporated into DNA with the axial substituent at $C(5)$ pointing in either the $5^{\circ}$ or the $3^{\prime}$ direction of the damaged strand. In isolation, as modeled by the quantum-chemical calculations, these two conformations of the modified base are enantiomers; however, inside DNA the two configurations will have different energies. Interactions of the modified base with other components of DNA are very different for these two configurations. An axial substituent at $\mathrm{C}(5)$ pointing in the $3^{\prime}$ direction will be located in the major groove of DNA whereas this substituent pointing in the $5^{\prime}$ direction w'ill result in significant steric clashes with the adjacent base.

Most of the MDS that we have carried out thus far have been for conformation $\mathbf{A}$ shown in Fig.(3). In this case, $\mathrm{C}(5)$ is displaced from the base plane in the $5^{\prime}$ direction and $C(6)$ is displaced in tine 3 direction of damaged strand. The accessibility of DNA bases to free-radical attack should favor conformation $\mathbf{A}$ for the following reasons. Since $\cdot \mathrm{OH}$ and $\cdot \mathrm{H}$ addition to pyrimidine bases is an attack on the r-electron system of a double bond. transition-state calculations (Miaskiewicz \& Osman, prepared for publication) show that the radicals must approach from a direction that is perpendicular to the base plane. Molecular modeling of the accessibiltiy of bases in B-DNA readily shows that radicals must approach the base from the 3 ' direction to satisfy the requirements on transition states for addition 'reactions. Hence, stable products in the A-type configuration with hydroxyl groups in the 3 ' direction should be more abundant. Details of the stereospecific mechanism leading to the formation of cis-thymine glycol in the $\mathbf{A}$ confromation are illustrated in Fig(4).

Production of pyrimidine lesions in the $\mathbf{B}$ configuration cannot be totally excluded because experimental data indicate the presence of two stereoisomers of cis-thymine glycol inside DNA 36. 37, presumably structures A and B in Fig(3). Structure B could result from OH-radical attack on DNA in a distoried geometry that allows accessibility to thymine from the 5 ' direction. Alternatively, an epimerization process iike that suggested by Lustig et al. 38 might explain the production of both stereoisomers by $\mathrm{OH}$ radicals approaching from the $3^{\prime}$ direction. Hence, while the remainder of this section is primarily devoted to 
MDS of DNA containing ring-saturated thymine lesions in type A configurations, the final paragraph will give a comparison of results for thymine glycol in both of the configurations shown in Fig.(3).

Since detalled analysis of a simulation is rather voluminous. only the most important results will be presented here. Surprisingly, all four of the ring-saturated thymine lesions that we have studied can be incorporated into DNA without significant perturbation of the pattern of backbone torsional angles. As illustrated in Fig.(5) for thymine glycol, the torsional angles around the lesion do not differ from those of other nucleotides in the dodecamer and are in the range expected for right-handed DNA structures. Hence, the DNA structure must distort in some other way to accomodate these modified bases. Fig.(6) shows that the Rise distance between the stacked bases of the damaged strand is dramatically affected by the bulky non-planar lesions. For thymine glycol and 5hydroxy-5,6-dihydrothymine, which have a pseudo axially oriented methy-1 group. the increase in Rise between $A 6$ and $T 7^{*}$ is accompandied by a decrease in the Rise between $T 7^{*}$ and T8. This effect is smaller for thymine hydrate and 5,6-dihydrothmine where the axially oriented substituent at $\mathrm{C}(5)$ is a less bulky hydrogen atom.

The time course of the length of Watson-Crick hydrogen bonds in base pairs at or near the lesion is shown in Fig.(7). All of the hydrogen bonds in a given base pair show essentially the same time dependence. Surprisingly, we find greater perturbation of the hydrogen bonds in the A6-T19 base pair than at the site of the lesion in all four cases. Since the largest perturbations of base pairing occur on the 5 ' side of the lesion and are most pronouced when the dodecarner contains thymine glycol or 5-hydroxy-5.6-dihydrothymine, it is reasonable to associate these effects on base pairing with the pseudo axially oriented substitents at $C(5)$. Clearly, base-stacking will also be compromised in the vicinity of the lesion due the increase in rise for the $A 6 / \mathrm{TP}^{*}$ step and the simultaneous decrease for the $\mathrm{T}^{*} / \mathrm{T} 8$ step that were discussed above in connection with the results shown in Fig.(6).

The pattern of DNA perturbation observed in our MDS is qualitatve similar for the four lesions; however the magnitude of the distortions clearly distinguishes thymine glycol 
and 5-hydroxy-5.6-dihydrothymine from thymine hydrate and 5.6-dihydrothymine. The major structural difference between these lesions is the orientation of the methyl group at the $C(5)$ position of the thymine ring, which is axial for the former pair and equatorial for the latter. Axial substituents at $C(5)$ are perpendicular to the base plane and cause significant steric clashes with the adjacent base in the $5^{\prime}$ direction. as is illustrated in Fig.(8). To accomodate these axial substituents the distance between the bases must increase significantly, as is appearent for the time dependence of the rise parameters shown in Fig.(6). This in tum perturbs the hydrogen bonding for the base pair located 5 ' to the lesion. Since a methyl group is significantly more bulky than a hydrogen atom, these distortions of DNA structure are significantly larger for thymine glycol and 5-hydroxy-5,6dihydrothymine than they are for thymine hydrate and 5.6-dihydrothymine. These results correlate very well with the biological consequences of the lesions described in the INTRODUCTION.

Variations in the Rise coordinate and the length of Watson-Crick hydrogen bonds observed in MDS of d(CGCGAATgTCGCG) $)_{2}$ when the axial methyl group of thymine glycol is oriented in the 3' direction of the damaged strand are shown in Fig.(9). In this case, perturbations in Rise occur primarily between $\mathrm{T} 8$ and $\mathrm{Tg} /$ but they are significantly smaller than that shown in Fig.(6) for the Rise between Tg7 and A6 when methyl group of thymine glycol is orientated in the $5^{\prime}$ direction. Hydrogen bond distances in T8-A.17 are not affected by these smaller changes in Rise so that, unlike the stereoisomer of thymine glycol with methyl pointing in the 5 ' direction, the major effect on base pairing is at the lesion site. These results clearly show the importance of the conformation adopted by ring-saturated pyrimidine lesions when formed inside DNA. An axial $\mathrm{OH}$ at $\mathrm{C}(6)$ pointing in the 5 ' direction produces significantly less distortion on the 5 ' side of the lesion than an axial methyl group at $C(5)$ with a similar orientation. Hence, for both stereoisomers of thymine glycol, the hydroxyl groups are mainly accommodated in the major groove of the double helic where they are easily accessible to water of hydration. On average, about 3 water molecules are found in close proximity to the hydroxyl substituents of thymine glycol at $C(5)$ and $C(6)$. The 
effect of these substituents on the electrostatic potential in the groove may play a role in recognition of the lesion by repair enzymes.

\section{RECOGNITION OF RING-SATURATED PYRIMIDINE LESIONS BY ENDOINUCLEASE III.}

Several features of endonuclease III facilitate molecular modeling of complexes between this Escherichia coli repair enzyme and DNA substrates that contain ring-saturated and ring-fragmented pyrimidine lesions. First, the enzyme does not require any cofactors and is active only on double-stranded DNA. Second, thymine glycol is a very effective inhibitor of the binding of endonuclease III to DNA containing lesions that are normally recognized by the enzyme 22 . This suggests that thymine glycol and lesioned DNA have the same binding site. Third, the binding site of thymine glycol has been identified crystalographically 26 to be a $\beta$-hairpin loop composed of amino-acid residues 113 through 119. This binding loop lies on a surface of the enzyme with a positive electrostatic potential that will engage long-range electrostatic interactions with negatively charged DNA. Finally, a high-resolution $x$-ray crystalographic structure of endo III has been determined 26 and atomic coordinates derived from this structure were kindly provided to us by Dr. John A. Tainer of the Scrippps Research Institute.

The first step in our modeling strategy to take advantage of these features is to investigate the interaction of thymine glycol (Tg) and the enzyme. The electrostatic potential at the surface of the protein calculated by the simplified DelPhi algorithm 39 included in the program GRASP by Anthony Nicholls, shows that while the vicinity of the loop has a higly positive potential, a region of negative potential in the center of the loop can be observed, that could enable efficient interaction with the positive charge on the hydroxyl groups of $\mathrm{Tg}$. Hence, we performed docking calculations between $\mathrm{Tg}$ and endonuclease III followed by energy minimizations performed with the AMBER force field. In all of the binding configuration that were identified, at least one of the hydrogen bonds involved the $\mathrm{C}=0$ groups of Glu 112, Leu 114, or Val 117. The location of these and other carbonyl groups on the exposed side of the binding loop is shown in Fig.(10). 
Three binding configurations for thymine glycol found by our procedure are shown in Fig.(11) along with their energies of interaction with the loop and with the entire protein. The most stable, configuration $\mathbf{A}$, has hydrogen bonds between the hydroxyl groups of $\mathrm{Tg}$ and $\mathrm{C}=\mathrm{O}$ groups of Leu 114 and Val 117 with lengths of 2.5 and $2.7 \AA$, respectively. In configuration $\mathrm{B}$, the hydrogen bond with the $\mathrm{C}=\mathrm{O}$ group of Val 117 is replaced by a hydrogen bond with an $\mathrm{N}-\mathrm{H}$ group of Gly 116. In configuration $\mathbf{C}$, which is stabilized primarily by a hydrogen bonds between $6-\mathrm{OH}$ and a $\mathrm{C}=\mathrm{O}$ group of Glu 112, the $\mathrm{N}(1)$ position of the pyrimidine ring lies close to Glu 112 and the pseudo axial methyl at $C(5)$ points into the loop. This contrast with configurations $\mathbf{A}$ and $\mathbf{B}$ for which $\mathrm{N}(1)$ is near Gly 118 and the 5Met $_{\mathrm{ax}}$ of $\mathrm{Tg}$ points out of the loop. Configuration $\mathbf{C}$ might be more favorable to the catalytic activity of endonuclease III than A or B, since Glu 112 and Lys 120 are currently the most

- likely candidates for the N-glycosylase and AP lyase activities, respectively. The advantage of $\mathrm{C}$ for AP lyase activity centered on Lys 120 is a consequence of the fact that the results illustrated in Fig.(11) are for (-)cis-5(R),6(S)-5,6-dihydroxy-5,6-dihydrothymine. Inside DNA, this stereoisomer of $\mathrm{Tg}$ will have the methyl group pointing in the 5 ' direction of the damaged strand: hence, the 3' side of the lesion, where the backbone will be cleaved by $\beta$ elimination, will be oriented in the direction of Lys 120 . Docking calculations with $(+)$ cis$5(S), 6(R)$-thymine glycol also revealed a binding configuration with these same advantages for the catalytic activity of the enzyme.

Fig.(12) shows the spatial relationship between a typical binding configuration of $\mathrm{Tg}$ and features of endonuclease III that are likely to be involved in interactions with DNA sequences. The second step in our modeling strategy is to superimpose $\mathrm{Tg}$ in the binding loop with the lesion in the dodecamer d(CGCGAATgTCGCG) ${ }_{2}$ from our MDS. Superposition of this DNA dodecamer on the $\mathrm{Tg}$ in its most stable configuration ( $A$ in Fig.(11)) gives a very reasonable starting structures for modeling the DNA-endonuclease III complex. DNA faces the part of the enzyme that shows positive electrostatic potential. The interaction between $\alpha$-helix 82-99 and the major groove of DNA can be also seen; however, steric clashes in the neighborhood of Lys 120 tend to cause intertwinement of the backbones of enzyme and 
substrate. To avoid this problem, the damaged DNA sequence must be shifted away from the protein. Refinement of the starting structures formed this way, lead to structures with the Tg of lesioned DNA much farther from the binding loop of the enzyme than is the case for binding of Tg in the absence of DNA. Hence, successful application of our modeling strategy will probably require molecular dynamics simulations to investigate the flexibilty of the protein structure, especially in the neighborhood of the binding loop, and the dynamics of the structures of both enzyme and DNA during the complex formation.

Tg also inhtbits the binding of urea-containing DNA by endonuclease III 22. Thus, it is reasonable to expect that the binding of urea-containing DNA to endonuclease III is similar to that for Tg-containing DNA. If the nonspecific global interaction of endonuclease III with d(CGCGAATTCGCG) 2 is independent of which of the two lesions (urea or Tg) replaces T7 in the dodecamer, then the optimum placement of the dodecamer in the complex with DNA containing Tg should provide a starting point for modifications in the neighborhood of the urea residue to achieve significant binding with the flexible $\beta$-hairpin loop. Modeling strategies of this type will be used to address the relative affinity of endonuclease III for different pyrimidine lesions.

\section{CONCLUSIONS:}

Our approach to modeling structure-function relationships for damaged DNA. sequences, that is based on quantum-chemical analysis of lestons in isolation followed by investigations of their impact on DNA structure though the use of semiempirical force fields, has several advantages over approaches that use NMR data as a starting point. The most obvious of these is that it can be immediately applied to lesions of interests for which NMR data are not currently available. An approach that does not require an experimental starting structure has the additional advantage that it can provide information on a given lesion that is not readily available from experiments and insights that come from comparison with closely related lesions. This advantage is illustrated in the current work by the $a b$ initio quantum results that reveal a relatively simple energetic basis for structural 
preferences among the many possible stereotsomers of ring-saturated pyrimidine lesions. General principles that emerge from investigation of related lesions can suggest new experiments to test the theory. The strong energetic preference for equatorally orientated $\mathrm{OH}$ at $\mathrm{C}(5)$ and the implications of this preference for the difference in perturbations of DNA structure by thymine and cyzosine glycol is an example of this process. Finally, an approach that does not require an experimental starting structure can more easily investigate the effects of a lesion on different DNA sequences.

The main disadvantages of our approach are the uncertainity of existing force fields for nucleic acids, the limited ability of MDS to sample the conformation space of solvated macromolecules with existing computer resourses, and the limited opportunity to check intermediate results by comparison with experimental data. Generally, the avallable experimental structures for modified pyrimidine nucleosides show that the results of our quantum calculations are very reasonable but direct comparison of theory and experiment is not possible without consideration of the effects of the ribose moiety. As sample preparation techniques improve and the avallability of NMR spectrometers increases, we expect to make more exacting tests of our modeling approach.

\section{ACKNOWLEDGEMENTS}

This work was supported by the Office of Health and Environmental Research (OHER) of the United States Department of Energy under contract DE-AC06-76RLO 1830 and DOE grant DE-FG02-88ER60675. We also gratefully acknowledge receiving atomic coordinates for endonuclease III from Dr. John Tainer of The Scripps Research Institute in La Jolla California.

\section{REFERENCES}

1. LUTZ, W. K. 1990. Mutation Res. 238: 287-295.

2. AMES, B. N. 1989. Mutation Res. 214: 41-46.

3. AMES, B. N. 1989. Environ. Mol. Mutagen. 14 (Suppl.16): 66-77. 
4. AMES. B. N. \& L. S. GOLD. 1991. Mutation Res. 250: 3-16.

5. TÉOULE, R. 1987. Int. J. Radiat. Biol. 51: 573-589.

6. DIZDAROGLU, M. 1991. Free-Radical Biol. Med. 10: 225-242.

7. LEADON, S. A. \& P. C. HANAWALT. 1983. Mutation Res. 112: 191.

8. BREIMER, L. H. \& T. LINDAHL. 1985. Biochemisty 24: 4018.

9. BOORSTEIN, R. J., T. P. HILBERT, R. P. CUNNINGHAM \& G. W. TEEBOR. 1990.

Biochemistrñ 29: 10455-10460.

10. GANGULY, T. \& N. J. DUKER. 1991. Nucleic Acids Res. 19: 3319-3323.

11. QUINLAN, G. J. \& J. M. C. GUTTERIDGE. 1991. Biochem. Pharmacol. 42: 1595-1599.

12. IDE, H., Y. W. KOW \& S. S. WALLACE. 1985. Nucleic Acids Res. 13: 8035-8052.

13. CLARK, J. M. \& G. P. BEARDSLEY. 1986. Nucleic Acids Res. 14: 737-749.

14. CLARK, J. M. \& G. P. BEARDSLEY. 1987. Biochemistry 26: 5398-5403.

15. HAYES, R. C. \& J. E. LECLERC. 1986. Nucleic Acids Res. 14: 1045-1061.

16. IDE, H., L. A. PETRULlO, Z. HATAHET \& S. S. WALlACE. 1991. J. Biol. Chem. 266: 1469-1477.

17. GANGULY, T. \& N. J. DUKER. 1992. Mutation Res. 293: 71-77.

18. IDE, H., R. J. MELAMEDE \& S. S. WALLACE. 1987. Biochemistry 26: 964-969.

19. SANCAR. A. \& G. B. SANCAR. 1988. Annu. Rev. Biochem. 57: 29-67.

20. LIN, J. \& A. SANCAR. 1989. Biochemistry 28: 7979-79\&4.

21. KOW, Y. W., S. S. WALLACE \& B. VAN HOUTEN. 1990. Mutation Res. 235: 147-156.

22. KOW, Y. K. \& S. S. WALLACE. 1987. Biochemistry 26: 8200-8206.

23. DEMPLE, B. \& S. LINN. 1980. Nature 287: 203-208.

24. BOORSTEIN, R J., T. P. HILBERT, J. CADET, R P. CUNNINGHAM \& TEEBOR, G. W. 1989. Biochemistry 28: 6164-6170.

25. GANGULY, T., K. M. WEEMS \& N. J. DUKER. 1990. Biochemistry 29: 7222-7228.

26. KUO, C.-F., D. E. MCREE, C. L. FISHER, S. F. O'HANDLEY, R. P. CUNNINGHAM \& J. A. TAINER. 1992. Science 258: 434-440. 
27. FRISCH, M. J., M. HEAD-GORDON, G. W. TRUCKS, J. B. FORESMAN, H. B. SCHLEGEL, K. RAGHAVACHAR, M. ROBB, J. S. BINKLEY, C. GONZALEZ, D. J. DEFREES, D. J. FOX, R. A. WHITESIDE, R. A. R. SEEGER, C. F. MELIUS, J. BAKER, R. L. MARTIN, L. R. KAHN. J. J. P. STEWART, S. TOPIOL \& J. A. POPLE. 1990. GAUSSIAN 90. Gaussian, Inc., Pittsburgh, PA.

28. RASHIN, A. \& B. HONIG. 1985. J. Phys. Chem. 89: 5588-5593.

29. HRUSKA, F. E., R. SEBASTIAN, A. GRAND, L. VOITURIEZ \& J. CADER. 1987. Can. J. Chem. 65: 2618-2623.

30. DUCOLOMB, R., J. CADET, C. TAIEB \& R. TEOULE. 1976. Biochim. Biophy. Acta 432: 18-27.

31. CADET, J., R. DUCOLOMB \& F. E. HRUSKA. 1979. Biochim. Biophys. Acta 563: 206215.

32. KONNERT, J., I. L. KARLE \& J. KARLE. 1970. Acta Cryst. B26: 770-778.

33. CADET, J., L. VOITURIEZ, F. E. HRUSKA, S-.L. KAN, F. A. A. M. DE LEEUW \& C. ALTONA. 1985. Can. J. Chem. 63: 2861-2868.

34. MLASKIEWICZ, K., R. OSMAN \& H. WEINSTEIN. 1993. J. Am. Chem. Soc. 115: 15261537.

35. PEARLMAN, D. A., D. A. CASE, J. C. CALDWEll, G. L. SEIBEL, U. CHANDRA SINGH, P. WEINER \& P. A. KOLLMAN. 1991. AMBER4.O. Univ. of California, San Francisco,CA.

36. SHARMA, M., H. C. BOX \& D. J. KELMAN. 1990. Chem.-Biol. Interactions 74: 10 i-117.

37. TEEBOR, G. W., A. CUMMINGS, K. FRENKEL, A. SHAW, L. VOITURIEZ \& J. CADET. 1987. Free Rad. Res. Commun. 2: 303-309.

38. LUSTIG, M. J., J. CADET, R. J. BOORSTEIN \& G. W. TEEBOR. 1992. Nucleic Acids Res. 20: $4839-4845$.

39. NICHOLLS, A. \& B. HONIG. 1991. J. Comp. Chem. 12: 435-445.

40. SAENGER, W. 1984. Principles of Nucleic Acid Structure. Springer-Verlag, New York. 41. RAVISHANKER, G., S. SWAMINATHAM, D. L. BEVERIDGE, R. LAVERY \& H. SKLENAR. 1989. J. Biomol. Str. Dyn. 6: 669. 


\section{FIGURE CAPTIONS}

1. Relationship between stereoisomers of 5,6-dihydroxy-5,6-dihydrothymine (thymine glycol). Results of electronic structure calculations carried out on the four isomers on the left side of the figure are given in Table 1 under the notation $5-\mathrm{OH}_{\mathrm{eq}}-6-\mathrm{OH}_{\mathrm{eq}}, 5-\mathrm{OH}_{\mathrm{ax}}$ $6-\mathrm{OH}_{\mathrm{ax}}, 5-\mathrm{OH}_{\mathrm{eq}}-6-\mathrm{OH}_{\mathrm{ax}}$, and $5 \cdot \mathrm{OH}_{\mathrm{ax}}-6-\mathrm{OH}_{\mathrm{eq}}$. The degeneracy of enantiomeric pairs in isolation will be removed in the asymmetric environment of a DNA macromolecule.

2. Intramolecular interactions between equatorial substituents in $5-\mathrm{OH}_{\mathrm{eq}}-5,6$ dihydrouracil (a) and in 6-OHeq-5.6-dihydrouracil (b).

3. Schematic of cis-5R-6S (A) and cis-5S-6R (B) stereoisomers of thymine glycol in DNA. Although they are degenerate in isolation, the isomers perturb DNA structure in different ways due to the difference in the interaction of axial substituents with neighboring bases.

4. Schematic of the reaction pathway leading to cis-5R-6S thymine glycol in DNA. (l) $\mathrm{OH}$ addition from the accessible 3 ' side gives an interinediate radical with spin density mainly on C(6). (II) Energetically preferred ring inversion allows oxygen to approach the radical intermediate from the accessible 3 ' side. (III) $\mathrm{O}_{2}$ addition at $\mathrm{C}(6)$ gives the more stable peroxyl radical. (IV) Further transformations of peroxyl radical leads to the stable product.

5. Time sequence of backbone torsional angles in a molecular dynamics simulation of d(CGCGAATTCGCG $)_{2}$ with $T 7$ replaced by thymine glycol. The standard Greek-letter designation for DNA backbone torsional angles 40 is used to identify the column of dials 41 that show the time course of the indicated torsion angle for the nucleotides in the lesioned strand of the duplex. The columns labeled by $\chi$ and $\phi$ show results for the glycosyl torsional angle and the pseudorotation of the sugar pucker, respectively. The radial coordinate is the time variable and the initial value of the torsional angle is indicated by a line from the center to the edge of the dial. Similar lines in the dials at the bottom of each columns show the standard values for $A$ and $B-D N A$. 
6. Time sequence of rise coordinates in d(CGCGAATTCGCG) $)_{2}$ when $T 7$ is replaced by a ring-saturated thymine lesion. Time increases from 60 to 120 ps between the bottom and the top of the windows. Horizonal axis is the rise in Angstroms for the indicated dinucleotide step.

7. Time sequence of Watson-Crick hydrogen bonds in d(CGCGAATTCGCG) ${ }_{2}$ when $T 7$ is replaced by a ring-saturated thymine lesion. Time increases from 60 to 120 ps between the bottom and the top of the windows. Horizonal axis is the separation in Angstroms between the hydrogen atom and the heavy atom invoked in hydrogen bonding. A solid and a dotted line are used to illustrate the two hydrogen bonds in A-T base pairs. A heavy line is added for the third hydrogen bond in the C-G base pair.

8. Snapshots showing the structure of DNA around the lesion site after 100 ps of molecular dynamics simulation on d(CGCGAAT TCGCG) 2 , where $T$ denotes a ring-saturated thymine base.

9. Fluctuations in rise and the length of Watson-Crick hydrogen bonds near the lesion in $d(C G C G A A T T C G C G)_{2}$, where $T *$ is cis-5S-6R thymine glycol with the pseudo axial methyl group pointing in the $3^{\prime}$ direction of the damaged strand. The methods used to display of the time sequences are the same as those described in Figs.(6) and (7).

10. Crientation of $\mathrm{C}=\mathrm{O}$ groups in the $\beta$-hairpin binding loop of endonuclease III with the greatest potential for hydrogen bonding with hydroxyl groups of thymine glycol. Dark filled circles indicate oxygen atoms in these groups that lie over the interior of the loop. Lighter filled circles denote oxygen atoms on the periphery of the binding loop but also on the surface that is accessible to DNA.

11. Three orientations of cis-5R-6S thymine glycol bound to the $\beta$-hairpin loop of endonuclease III found in energy minimizations. Thymine glycol-protein and thymine glycol-loop interaction energies are in $\mathrm{kcal} / \mathrm{mole}$.

12. Spatial relationship for the most stable binding configuration found for cis5R,6S thymine glycol and structural elements of endonuclease III believed to be important in recognition of DNA damage. 

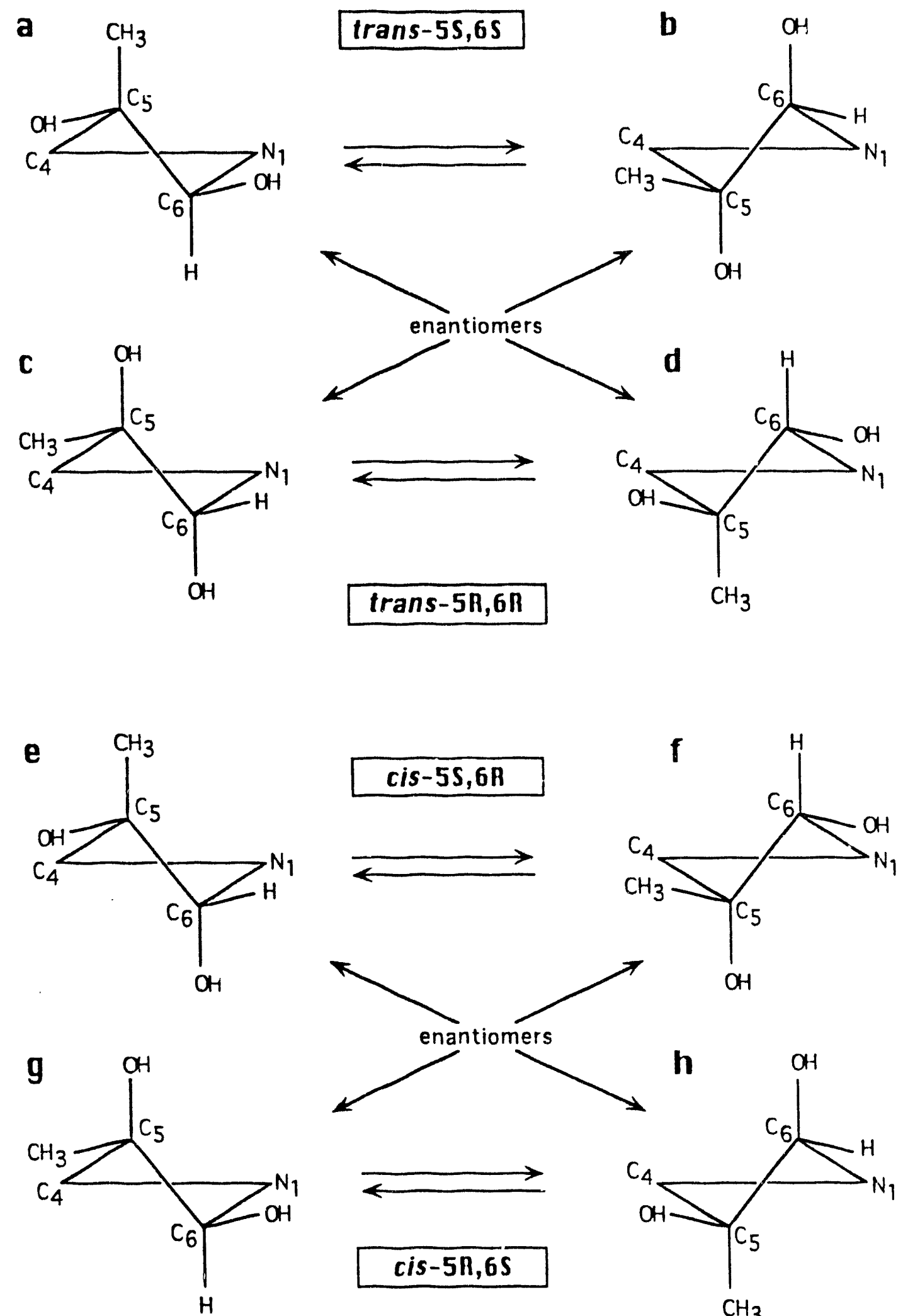

$\mathrm{CH}_{3}$ 
a)

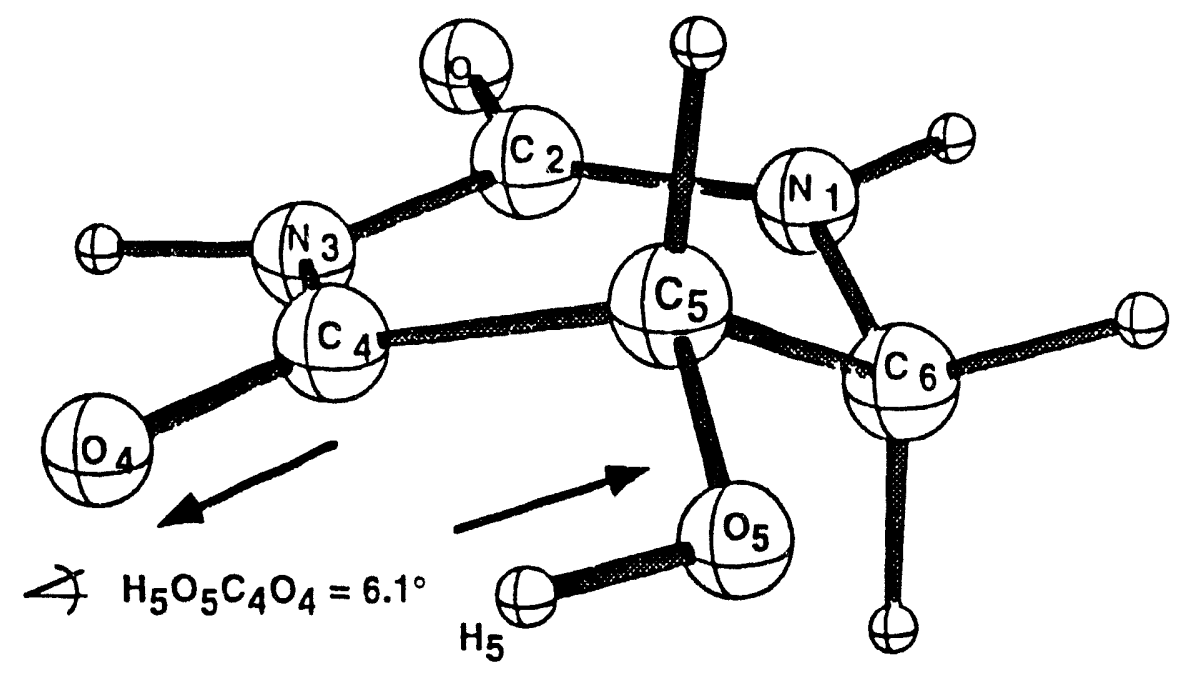

b)

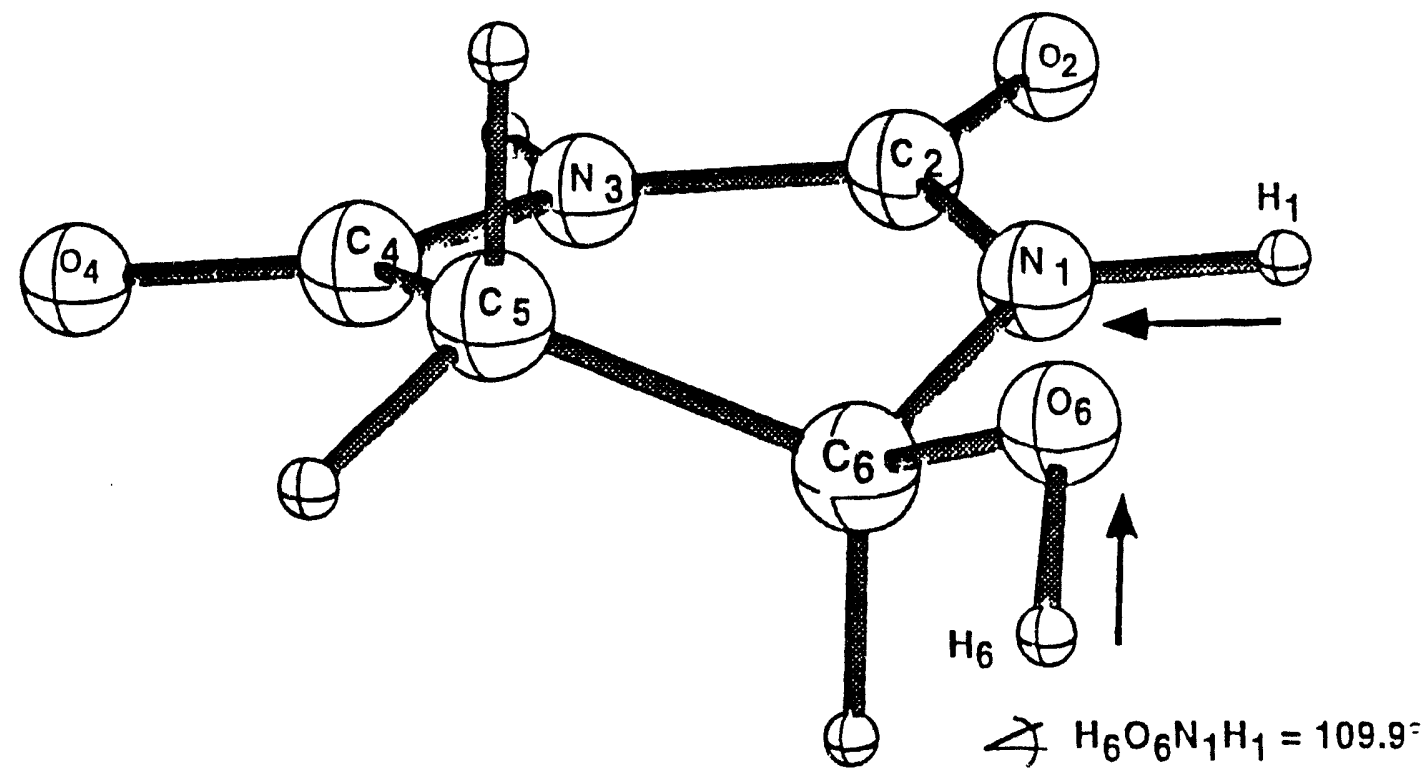


A.

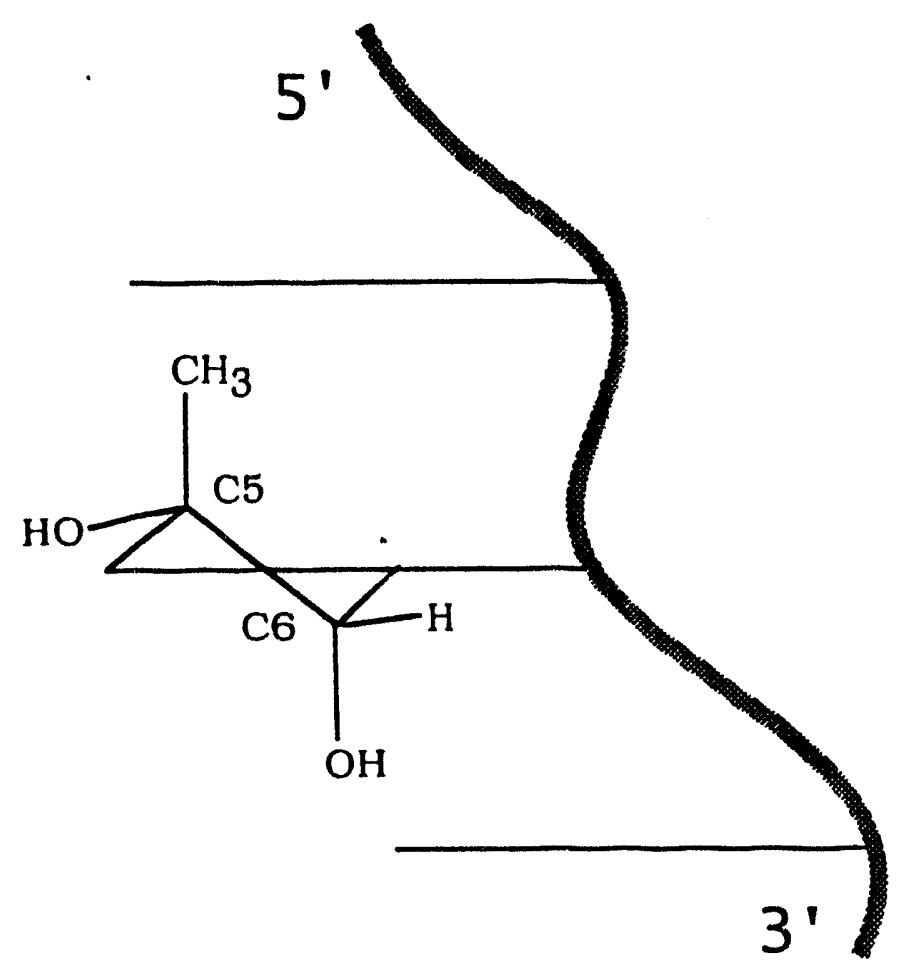

B.

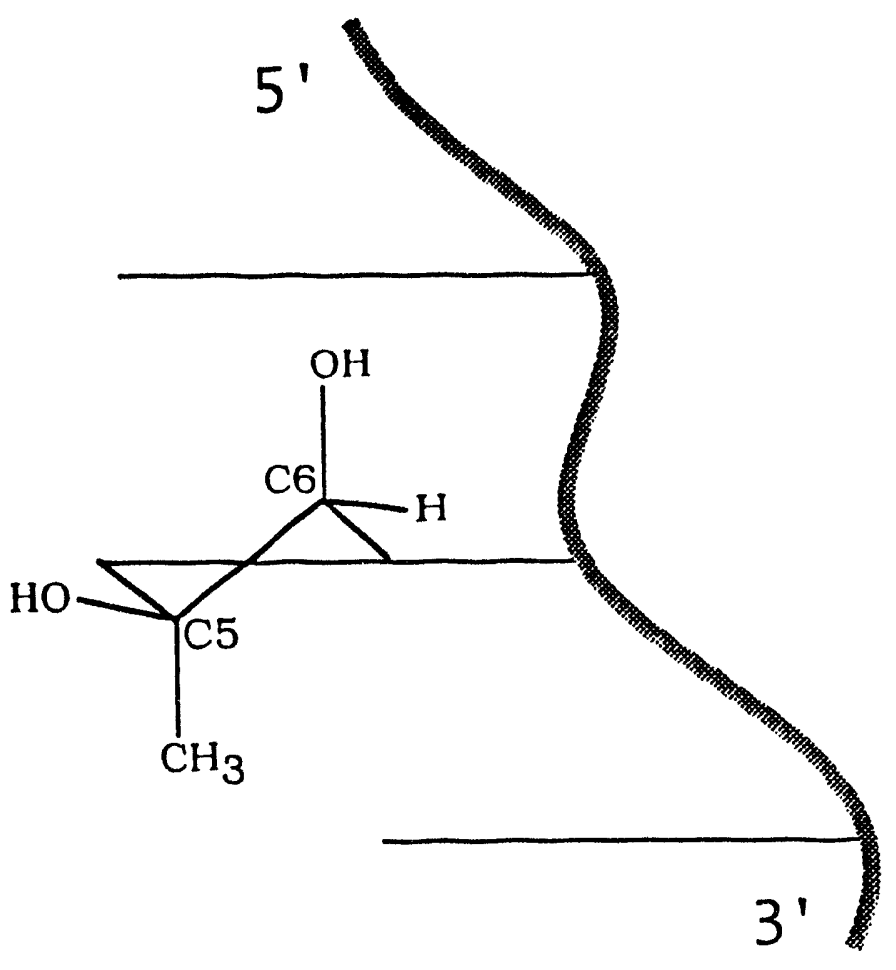

Fin? 

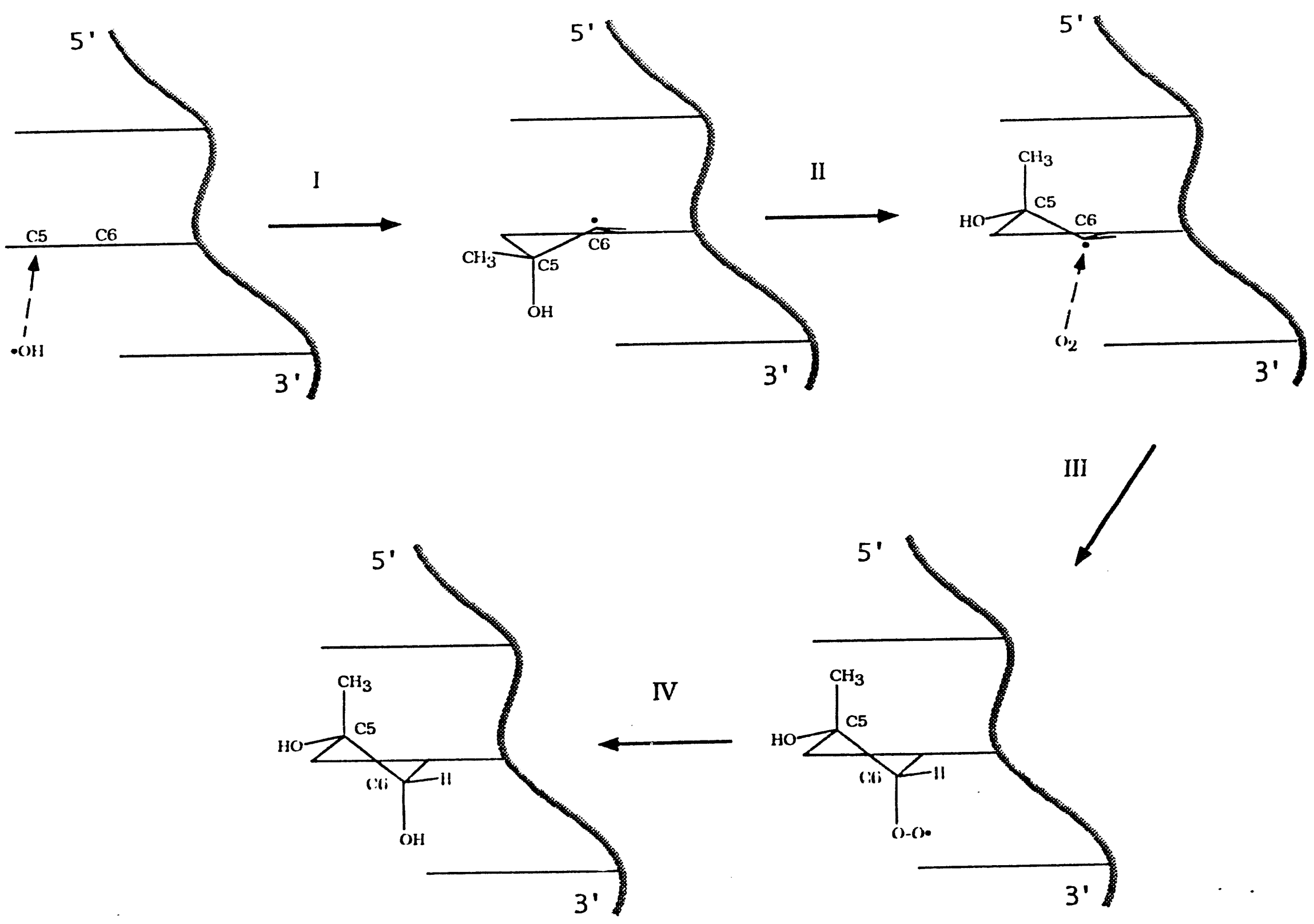

Fin.4 


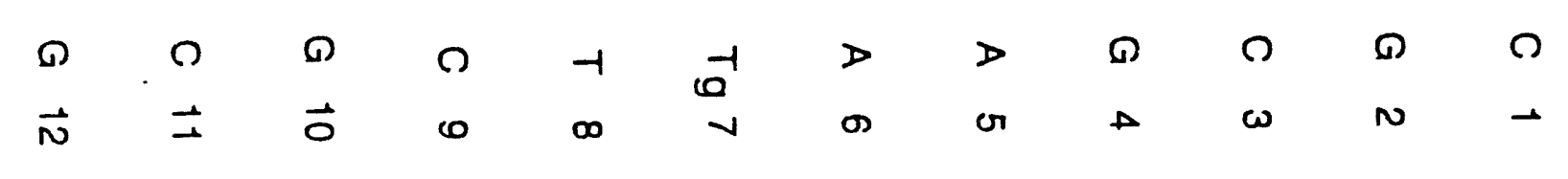

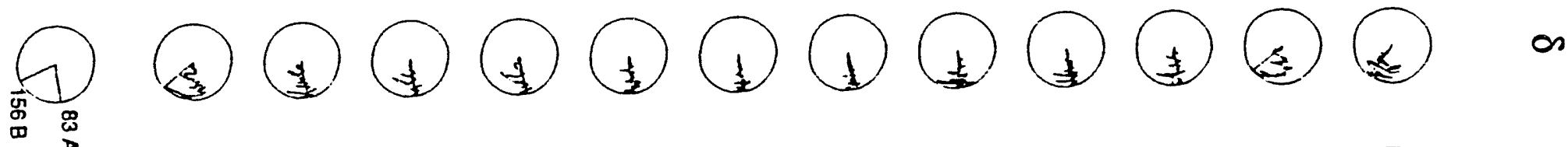
. 00000000000.

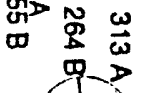

$(1$.

(

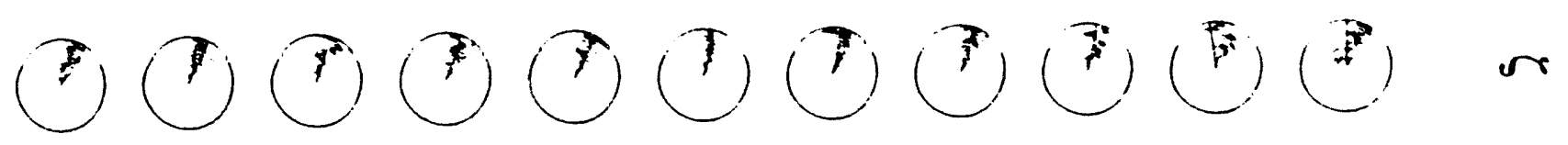
$00000000000=$ 艁

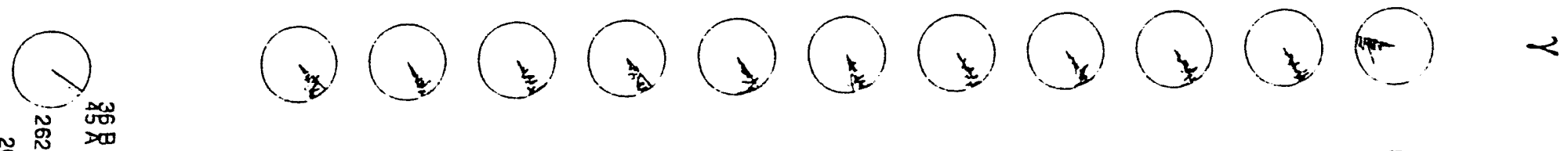

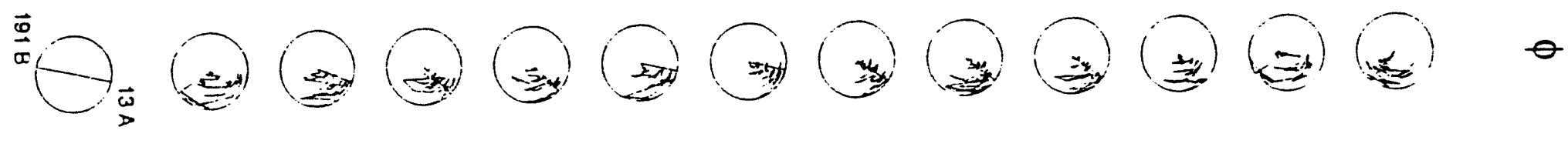


5,6-dihydroxy5,6-dihydrothymine
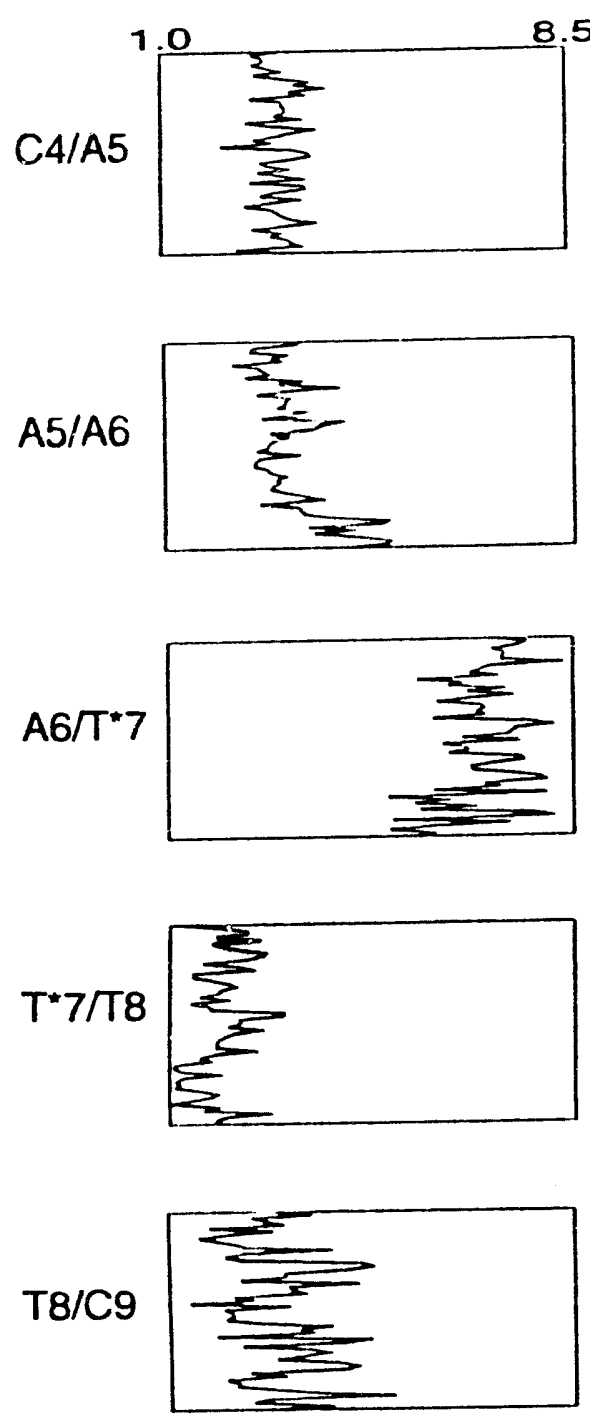

RIS 5-hydroxy5,6-dihydrothymine
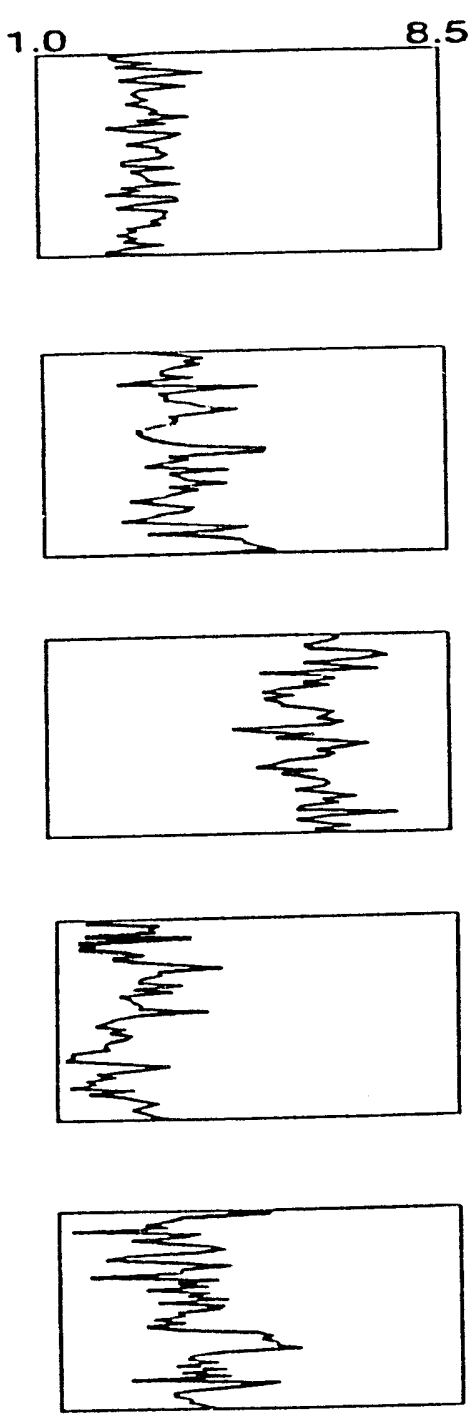

RIS 6-hydroxy5,6-dihydrothymine
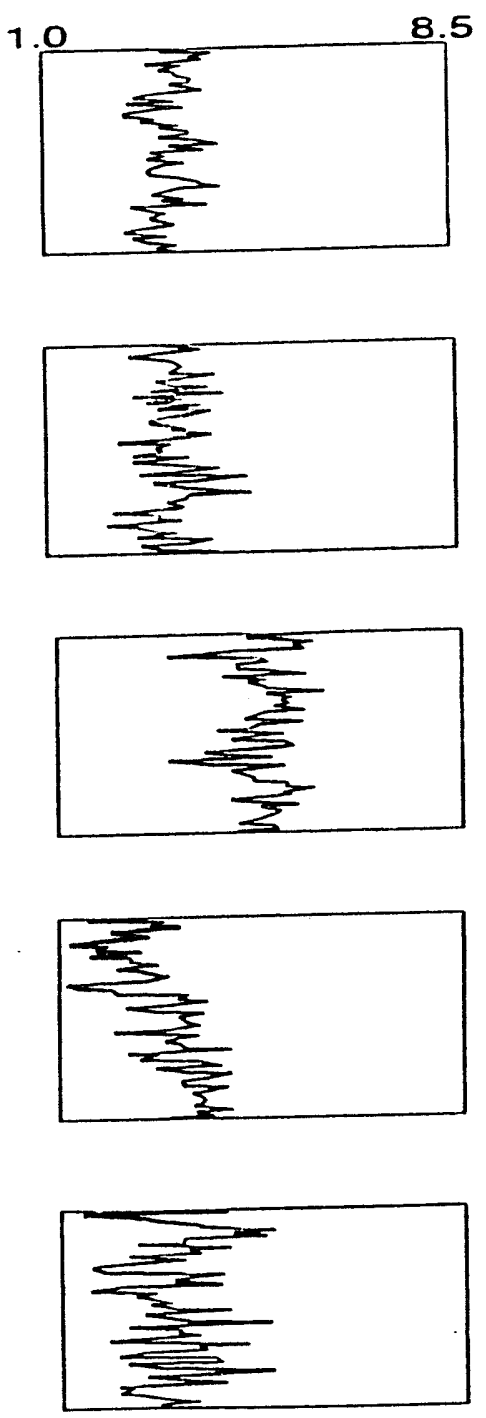

RIS

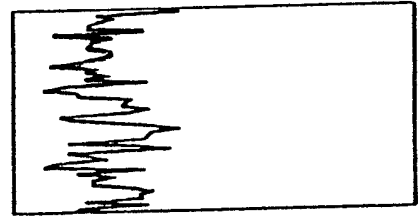

5,6-dihydrothymine
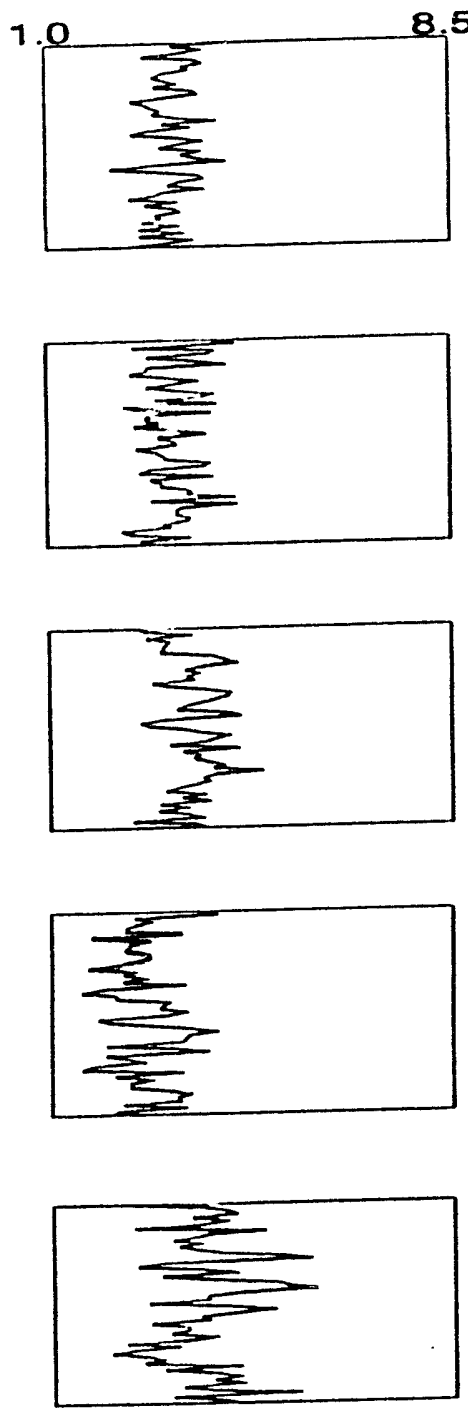

RIS 
5,6-dihydroxy5,6-dihydrothymine
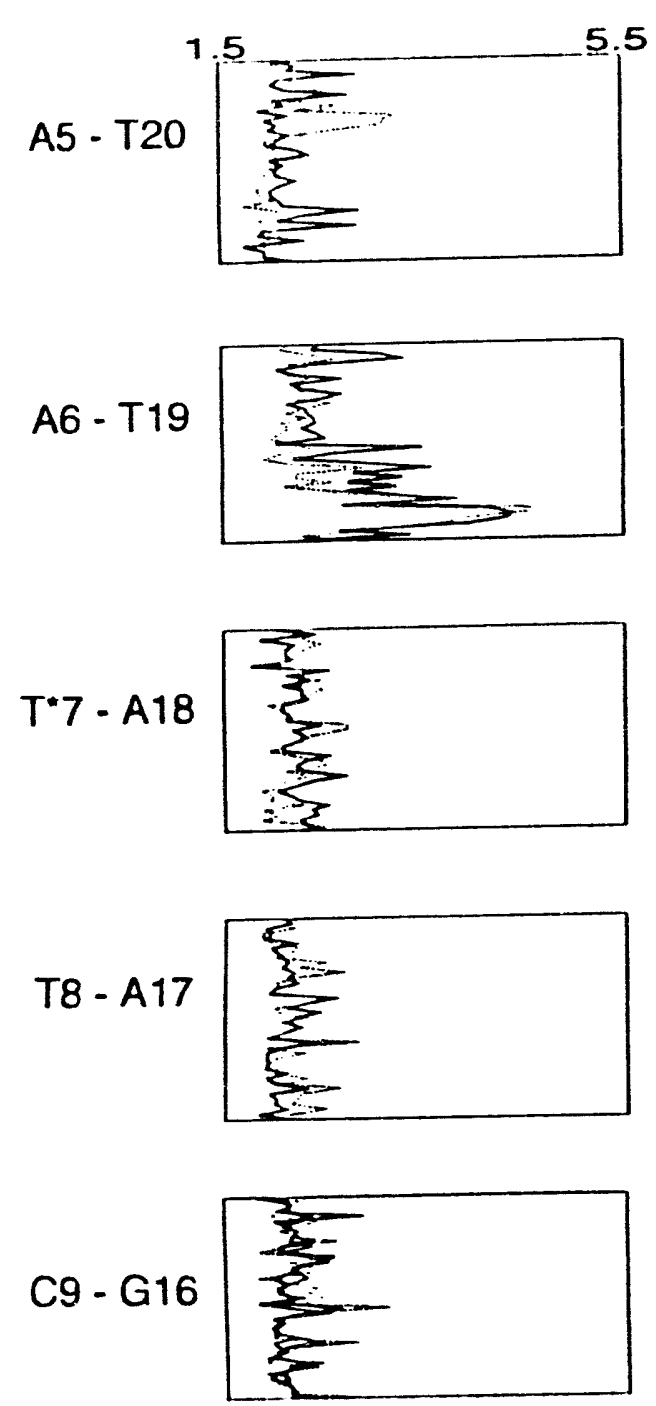

5-hydroxy5,6-dihydrothymine
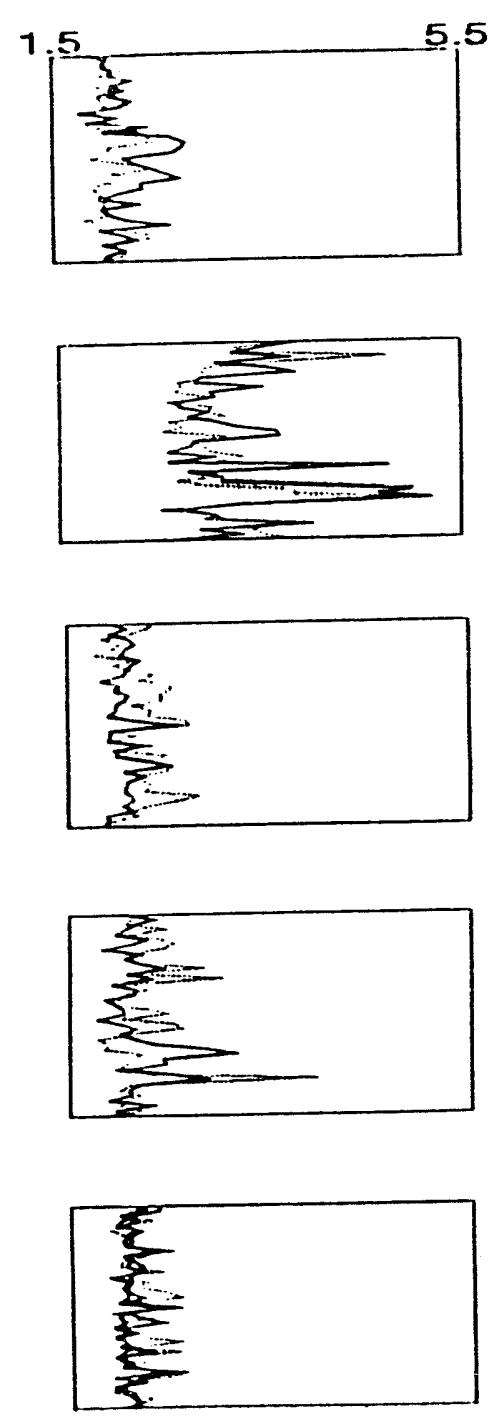

6-hydroxy5,6-dihydroihymine
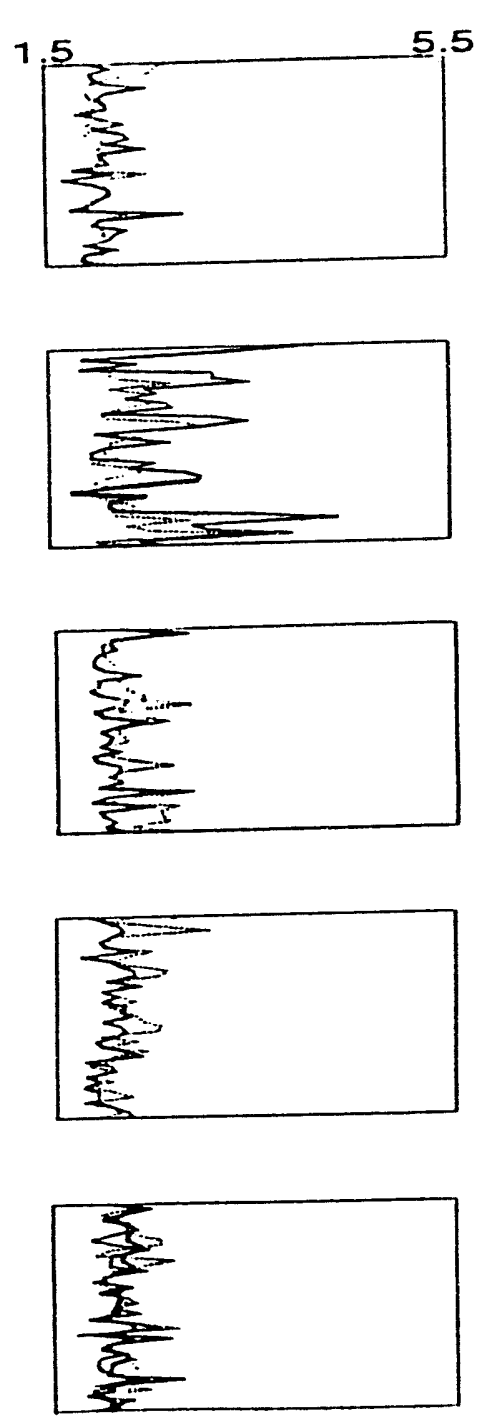

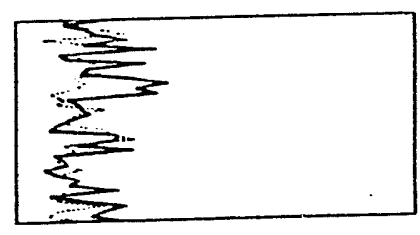

5,6-dihydrothymine
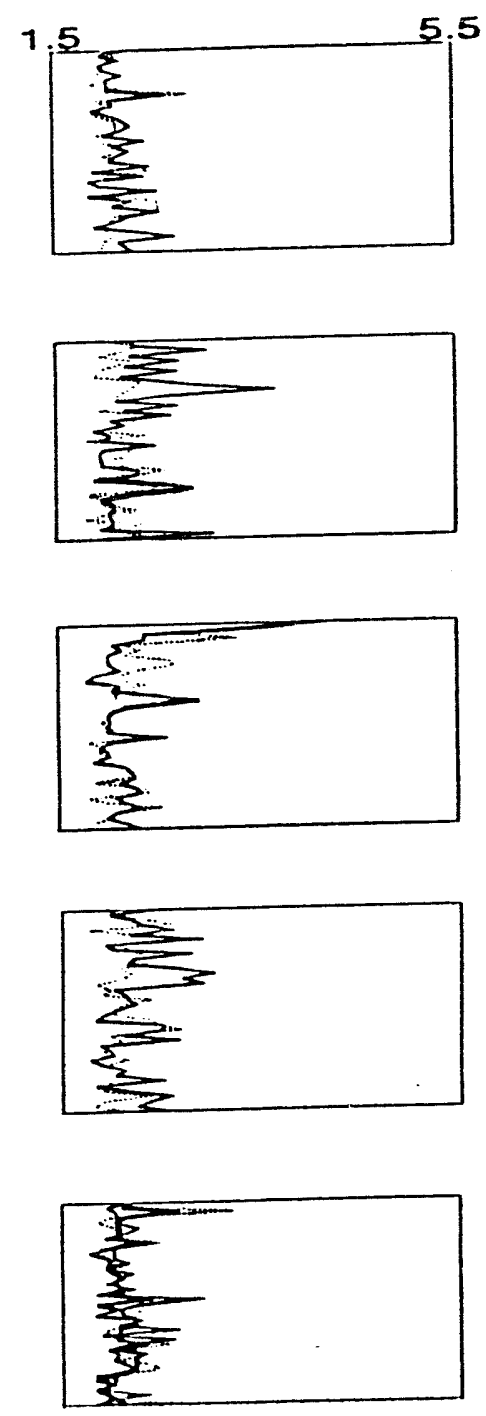
5,6-dihydroxy5,6-dihydrothymine
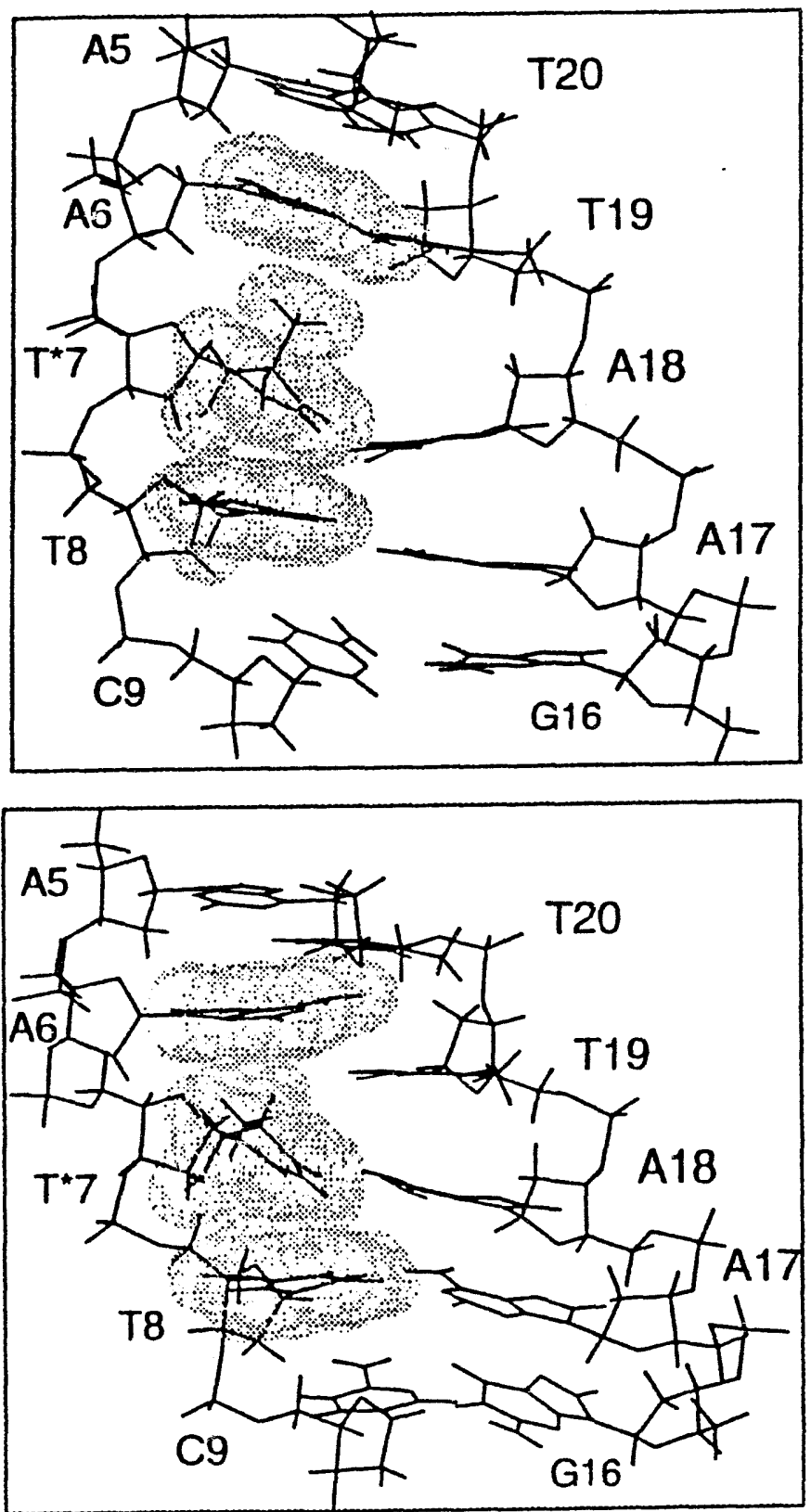

6-hydroxy-

5,6-dihydrothymine 5-hydroxy-

5,6-dihydrothymine
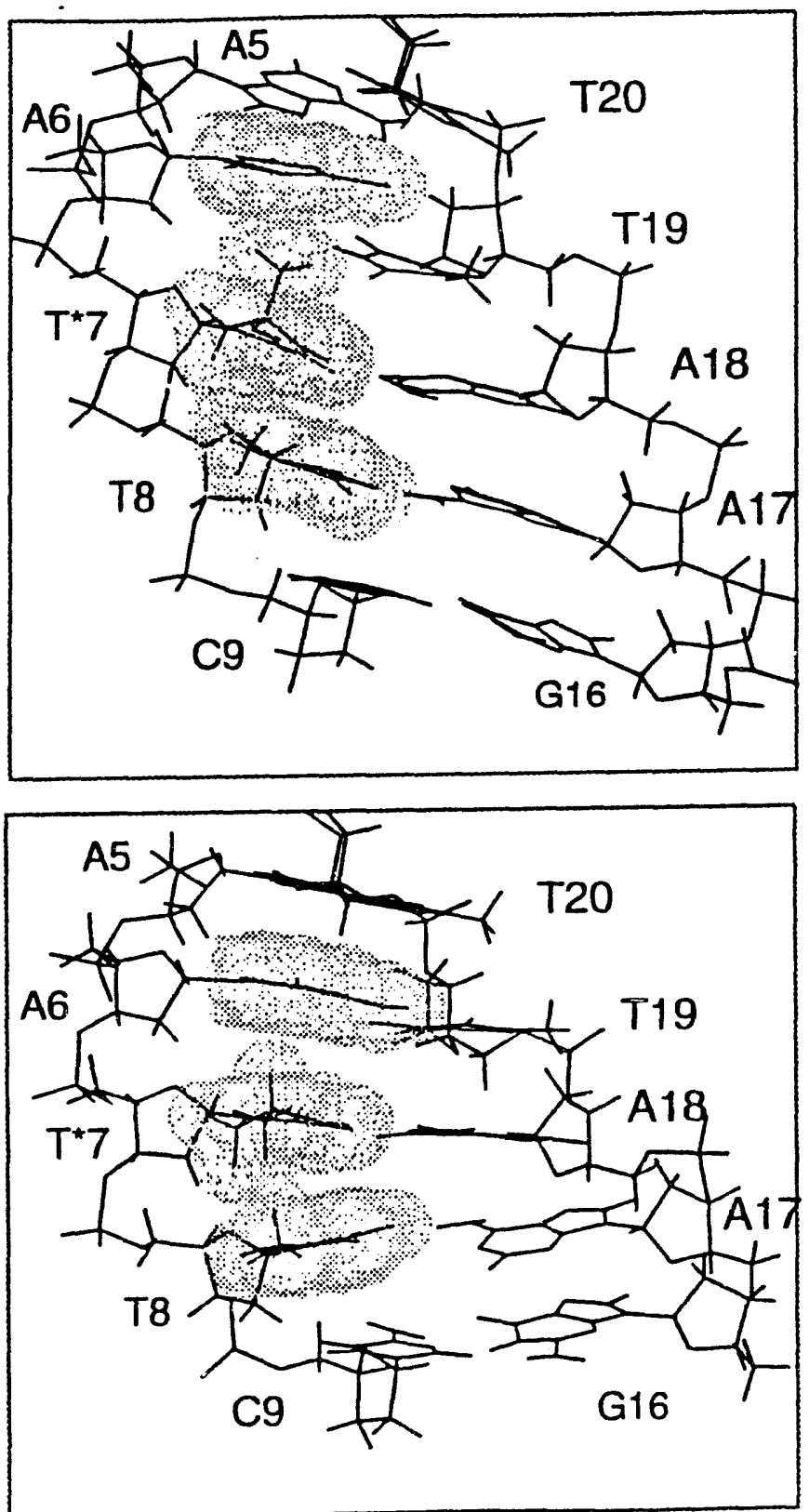

5,6-dihydrothymine 

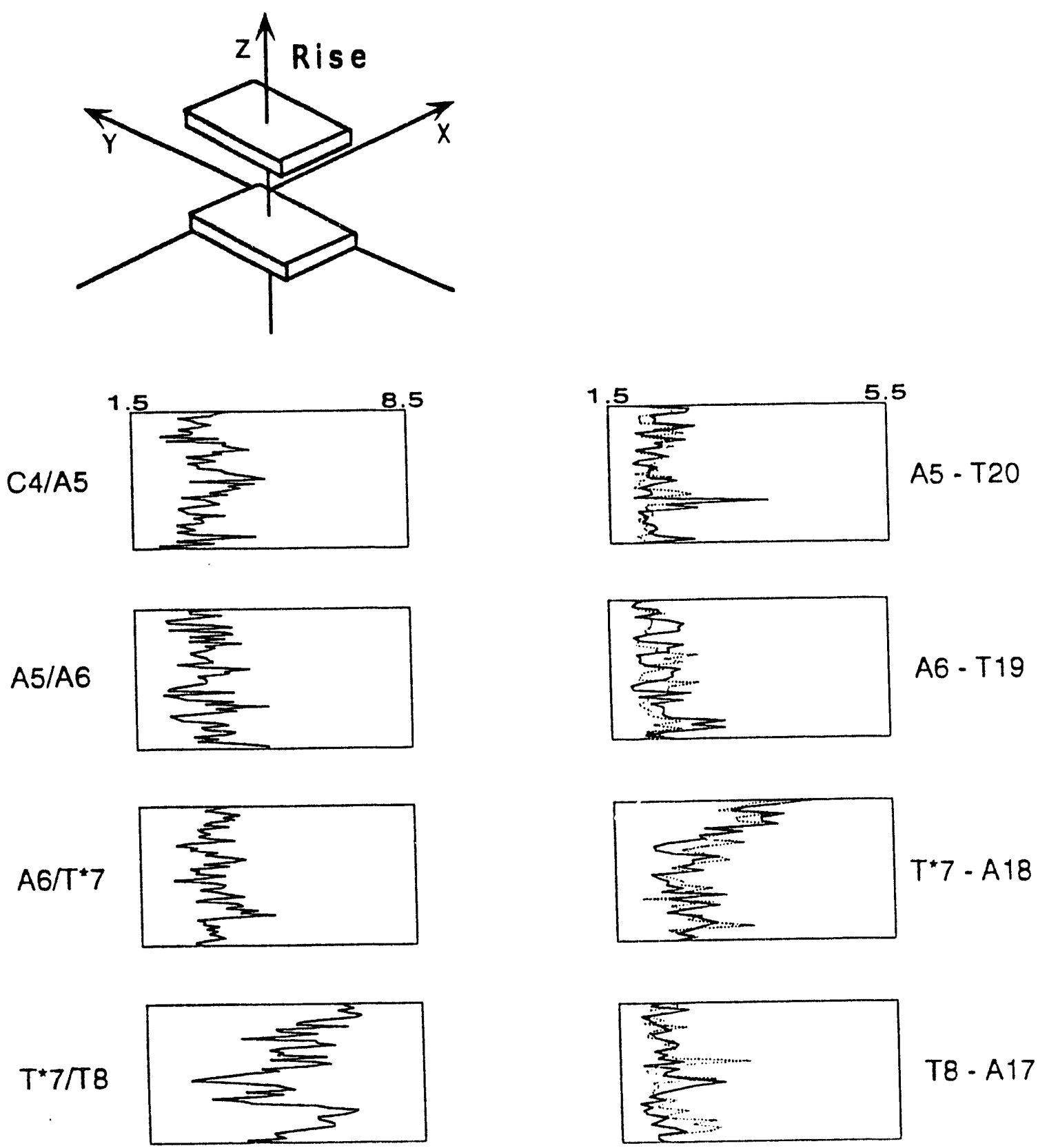

\section{T8 - A 17}
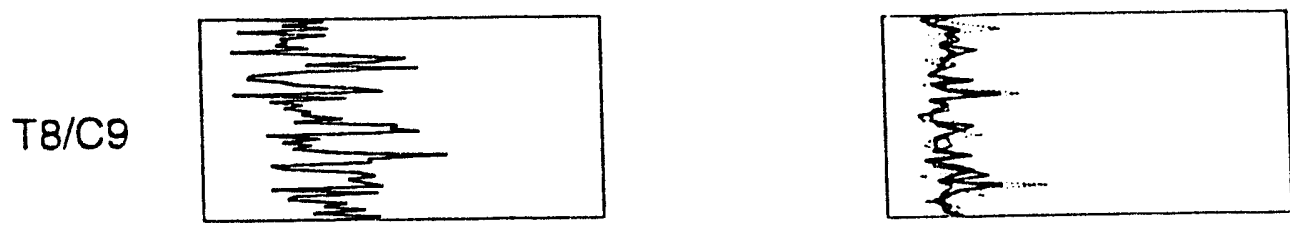

C9-G16

PIS

Hbonds 


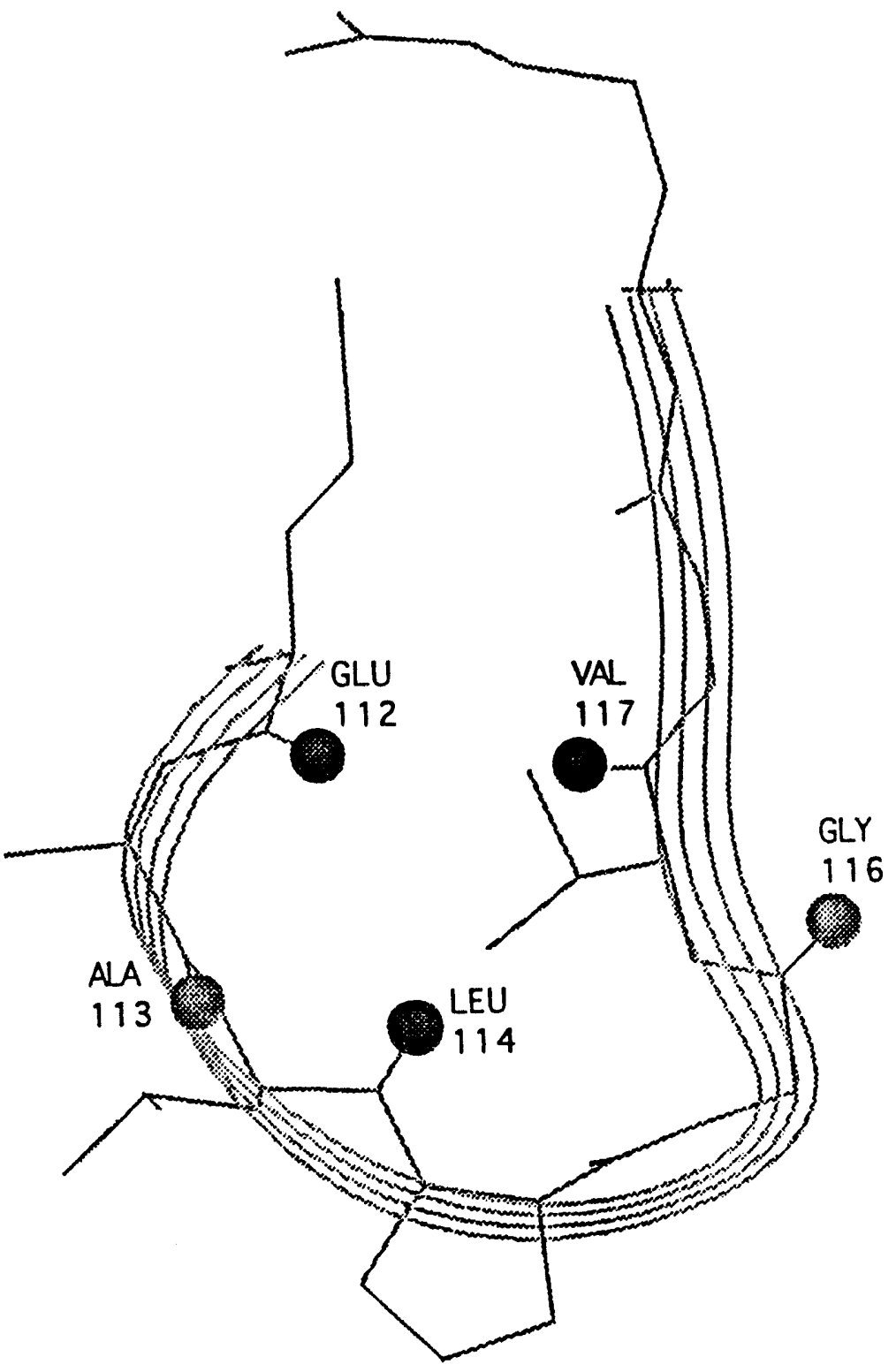

$F_{1} .10$ 


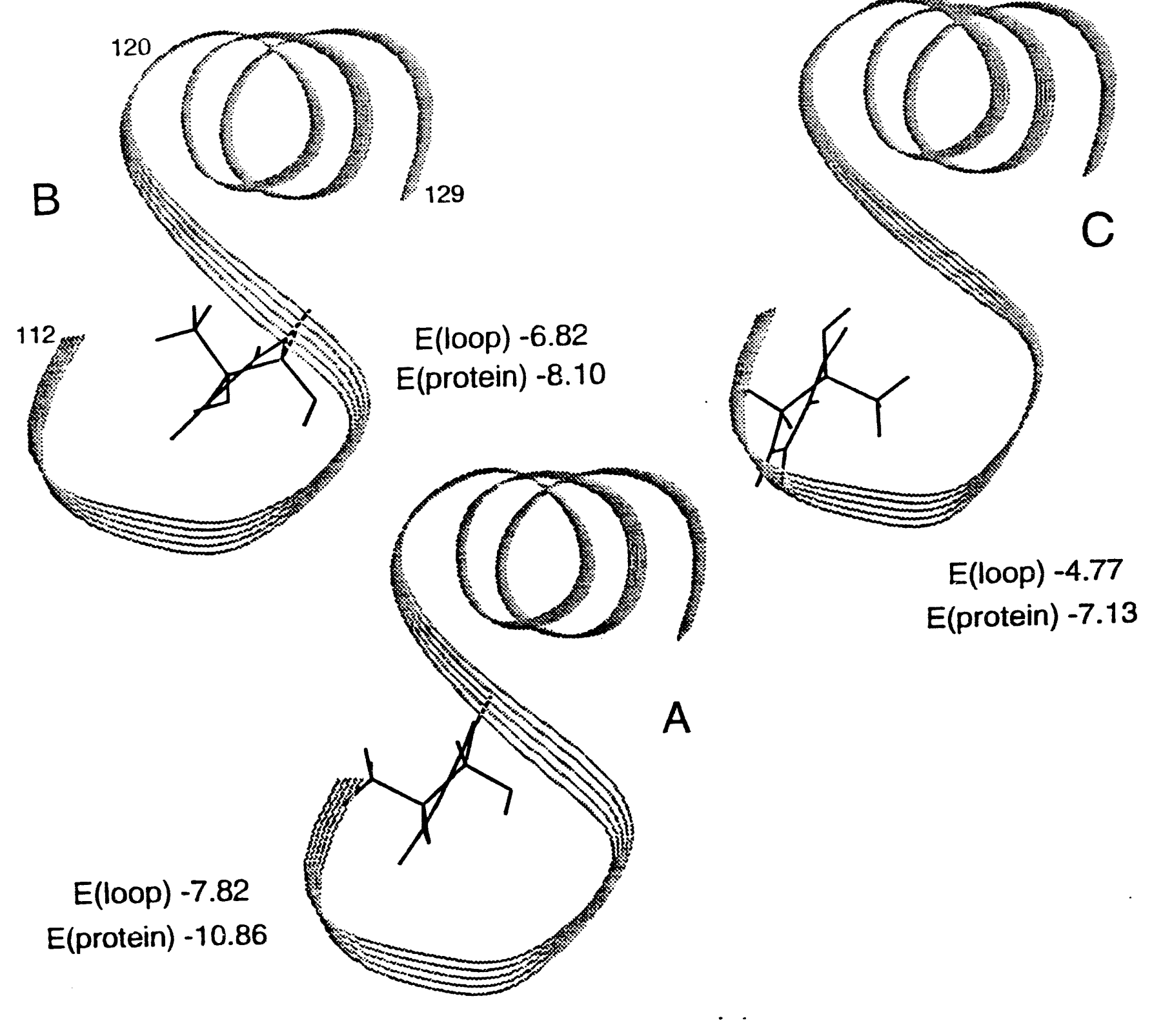




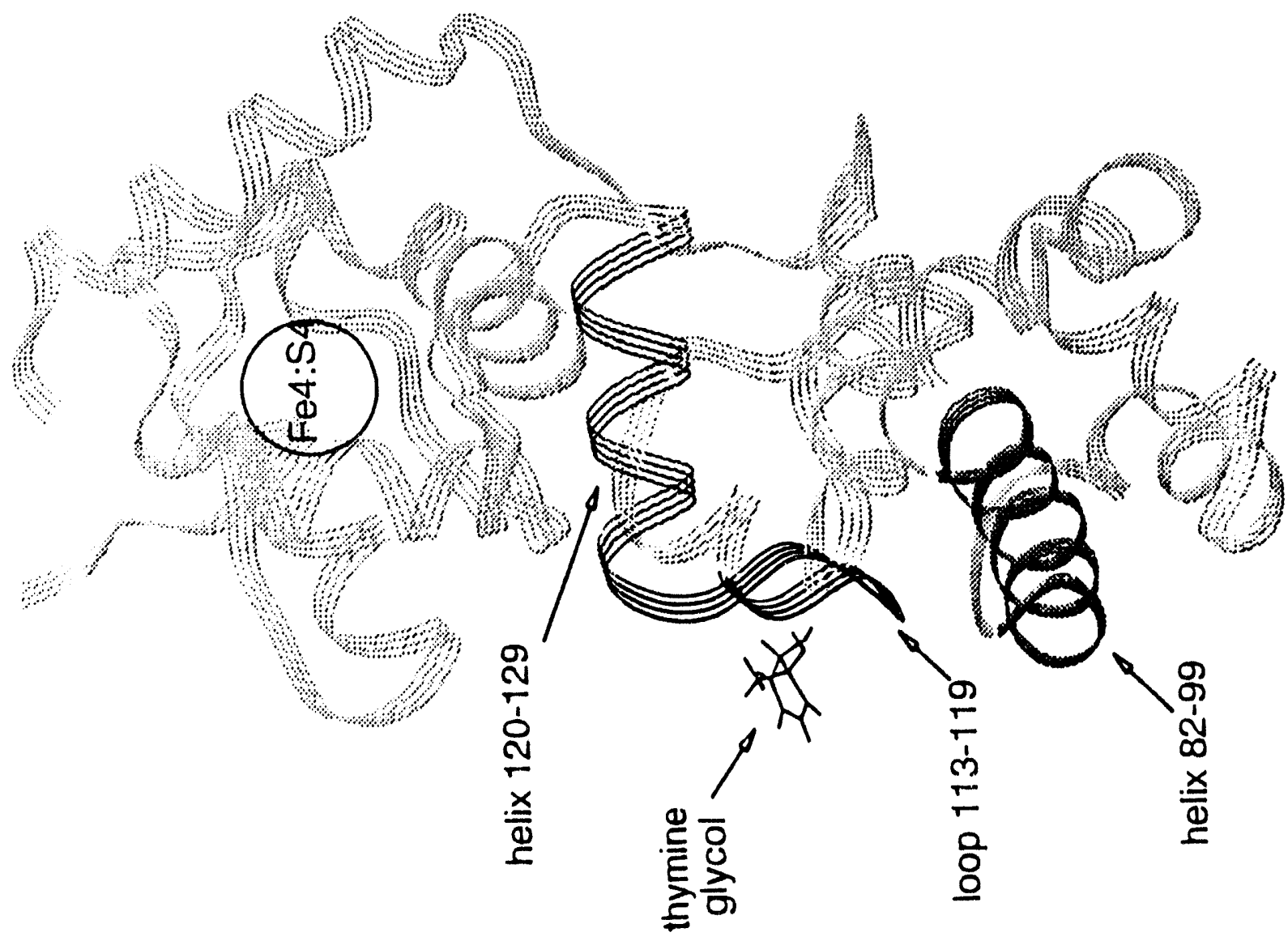




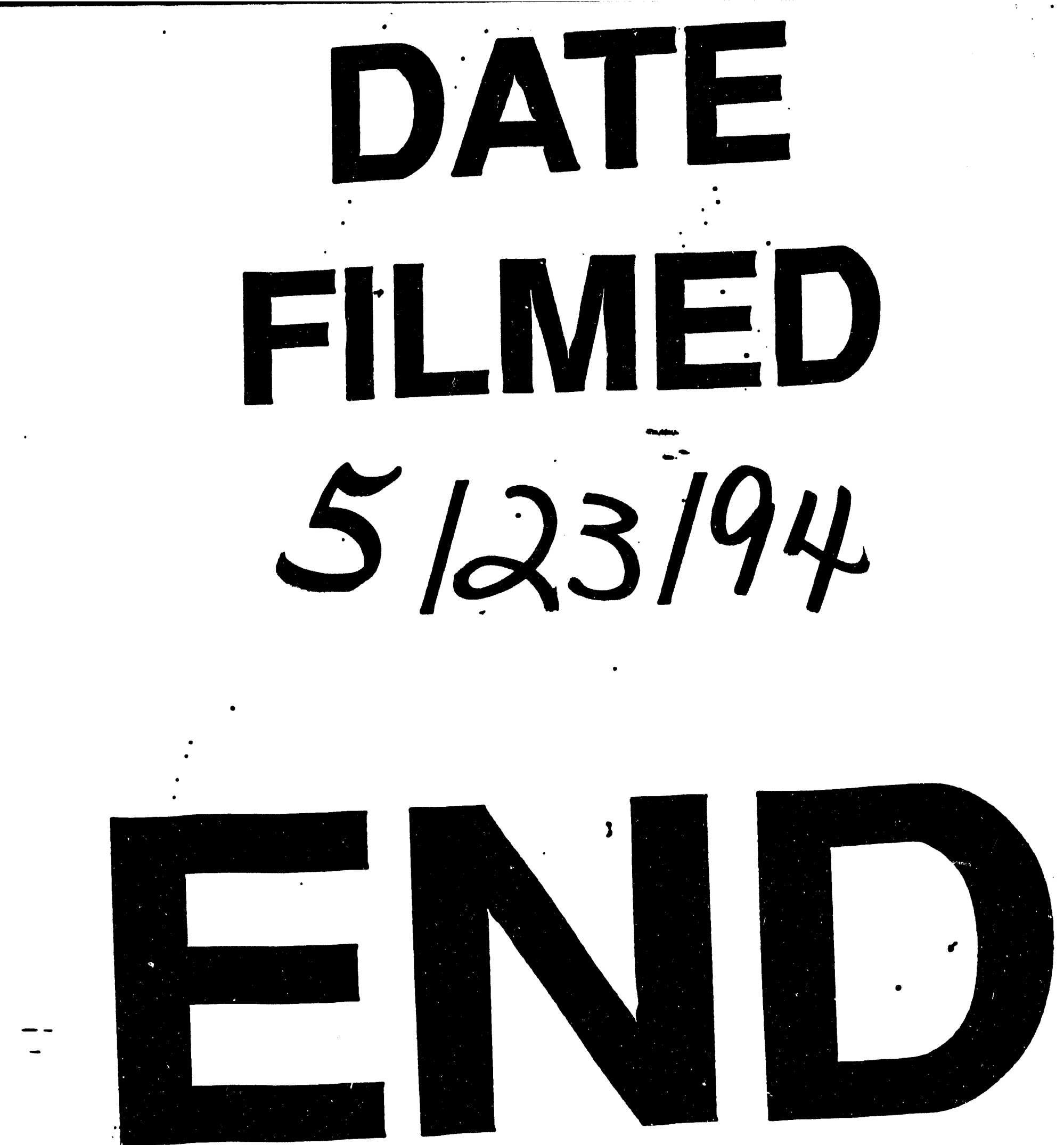




$$
\text { - }
$$

